\title{
Improved Super Twisting Based High Order Direct Power Sliding Mode Control of a Connected DFIG Variable Speed Wind Turbine
}

\author{
Zouheyr Dekali*, Lotfi Baghli¹,2, Abdelmadjid Boumediene $^{1}$ \\ ${ }^{1}$ Laboratoire d'Automatique de Tlemcen LAT, Université de Tlemcen, 13000 Tlemcen, P.O.B. 119, Algeria \\ 2 Groupe de Recherche en Energie Electrique de Nancy (GREEN), Université de Lorraine, F-54500 Vandoeuvre-lès-Nancy, \\ P.O.B. EA 4366, France \\ *Corresponding author, e-mail: zouheyr.dekali@univ-tlemcen.dz
}

Received: 05 February 2021, Accepted: 13 April 2021, Published online: 19 October 2021

\begin{abstract}
This work presents the theoretical and practical comparison of linear and nonlinear control laws for the direct power control of a gridconnected double fed induction generator (DFIG), based wind energy conversion system (WECS) under different operating modes. We will show the improvement brought by the super twisting based high order sliding mode control to mitigate the chattering phenomenon, due to the high switching frequency. It will also avoid the hyperlink of the controller settings to the system's mathematical model and will reduce the sensibility to external disturbances. The overall structure of the proposed control requires the use of the DFIG simplified model with field-oriented control (FOC). This last allows an instantaneous decoupled control of the DFIG stator active and reactive power by acting on $d q$ rotor currents $\left(I_{q r}, I_{d r}\right)$ respectively. In the preliminary tests, a comparative study is conducted to verify the superior performance of the proposed WECS control scheme during various operating modes including the maximum power point tracking MPPT mode. The study reveals the effectiveness of each implemented control law with its advantages and drawbacks. Keywords
\end{abstract}

double fed induction generator, direct power control, sliding mode control, super twisting, chattering, MPPT

\section{Introduction}

The cumulative global capacity of wind power production has grown rapidly in the last few years, where the rate is now over $651 \mathrm{GW}$. There is an increase of $10 \%$ compared to 2018, with new installations surpassing the 60 GW. 2019 is thus the second-best year historically for the global wind industry, but COVID-19 effects on the market outlook are still to be quantified [1].

Nowadays, the wind power system WPS can be classified into two basic types depending to the main topology $[2,3]$. The first class is the fixed speed concept, it was used for early WPS implementations. This kind operates at an almost fixed speed thanks to the topology which consists of the direct connection of the generator which is often a squirrel cage induction generator (SCIG) to the electrical grid through a transformer Fig. 1(a). The simplicity of this configuration and the reduced cost may also be an advantage in some applications. Nevertheless, there are some drawbacks. High wind speeds cause mechanical stress, the latter requires a more expensive mechanical construction to absorb high mechanical damping and a stiff power grid to allow a stable operation. Add to this, the produced power is limited and relatively low because of the operating speed. The second WPS class, which is widely widespread nowadays, is called variable-speed concept, which splits into two types [4]:

- Variable-speed concept based WPS with fully rated power converters Fig. 1(b), are mostly equipped by Permanent Magnet Synchronous Generator (PMSG), Multipoles Synchronous Generator (SG) or Induction Generator (IG). This system is able to operate at varying speeds of winds thanks to the power electronics converter that takes full control of the generator. It gives a good yield and also isolate the generator from the power grid. It lessen the sensitivity of the generator to grid voltage disturbances, but at the same time, it presents the major drawback of extra cost $[5,6]$.

- Variable-speed concept based WPS with partly rated power converters: Fig. 1(c) which is less expensive 


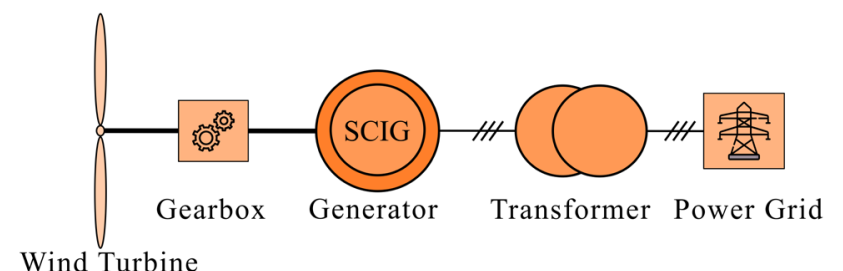

(a)

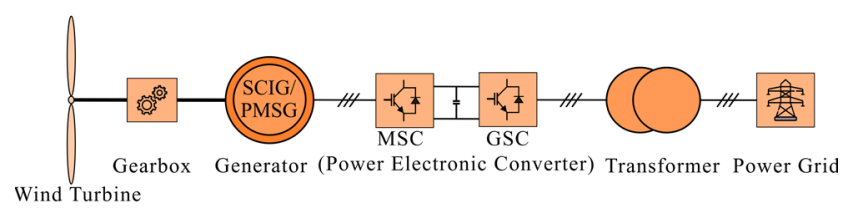

(b)

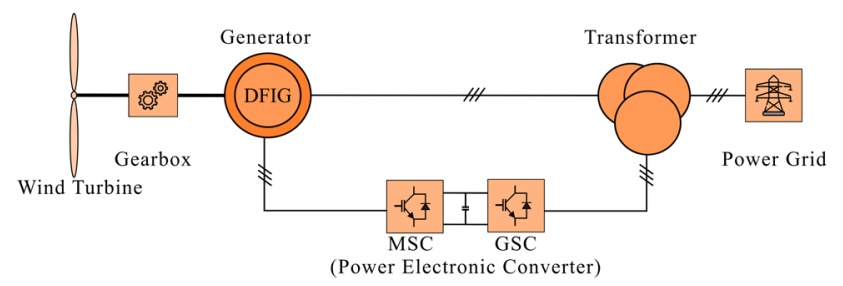

(c)

Fig. 1 Wind turbine topologies; (a) Fixed-speed concept based WPS; (b) Variable-speed concept based WPS with fully rated power converters; (c) Variable-speed concept based WPS with partly rated power converters

compared to the previous topology. The double fed induction generator DFIG is the most adopted one in this type. This WPS is also controlled under variable wind speed through the partial power electronic converter which decouples the DFIG rotor from the power grid, while the DFIG stator is directly linked to the power grid. The generator is more sensitive to the grid harmonic distortions in this configuration $[7,8]$.

Recently, the DFIG topology based WPS was used extensively as an efficient techno-solution for the electromechanical conversion thanks to its high reliability and attractive cost. This topology consists of the interrelatedness of the rotor windings and the power grid via the back-to-back converter which is composed mostly of two two-level pulse-width-modulation voltage-source-converter (2L-PWMVSC). The stator windings are connected directly to the power grid through a transformer. The main advantage of this relatively simple structure is the full controllability of the power flow of the stator by acting on the rotor currents. Besides this, it allows $30 \%$ of the power rating for the rotor power converters in order to achieve a nominal power transfer to the power grid [9]. According to the actual DFIG operating mode, when the system is in hypersynchronous operation, the grid side converter (GSC) works as an inverter, where he has the role for both adjusting the DC-bus voltage and controlling the power flow of the active power to the grid. It also ensures a fixed power factor. The motor side converter (MSC) operates as a rectifier and supplies the DC voltage to the GSC from the rotor windings while keeping control of the stator power delivery. During the hypo-synchronous operating mode, the operation is reversed between the MSC and the GSC, thus the GSC which becomes the rectifier delivers the DC voltage to the inverter which is the MSC. In this case, the rotor consumes energy and only the stator can produced it [3].

Direct power control (DPC) is based on the field-oriented control FOC theory using conventional PI controllers. It is known as an effective solution to robust tracking accuracy and high robustness. Hence, the benefit of this technique is the control of stator active/reactive power through direct/ quadrature rotor currents in an instantaneous and decoupled way between the $d q$ axis components. However, the PI controller settings are tuned according to the internal parameters of the machine, which decreases the robustness consequently and a risk of system instability [10, 11].

Since the 1990s, sliding mode control became popular as a good choice instead of PI controllers. It is easy to implement and provides robustness against the internal parametric variations [12]. On the other hand, the chattering phenomenon caused by the high commutation frequency is the major drawback of this technique. This phenomenon can be reduced by replacing the discontinuous term by the smooth function or by the use of the exponential reaching law. The high order sliding mode approach presents another typical effective solution to eliminate the chattering problem, by keeping the same first-order sliding mode behaviors, especially the convergence properties and the control accuracy [13]. The super-twisting algorithm is an exception in a class of second-order sliding mode control, it can reduce chattering problems due to the discontinuity of the control signal [14].

The topic of this paper concerns the domain of clean energy production that our laboratory is working on this last decade. Hence, we developed knowhow while studying and developing this kind of systems for national needs in the field of renewable energy and micro power plants. Furthermore, the works carried out in [9] and [15], focuses on the experimental implementation of a grid-connected wind energy conversion emulator based on the DFIG. The power HIL was tested successfully, including electrical 
machines, power electronic converters and its control programs. The DFIG PI linear control law is effective. However, a nonlinear control law would be more flexible in order to improve the quality of the control and reduce the operating constraints.

The structure of this paper is organized as follows: the first part describes in detail the overall proposed wind energy conversion system based on DFIG variable speed drive. Section 2 gives a detailed study on a variable speed WPS improved by applying the principle of MPPT. The third part illustrates the dynamical model of the DFIG including its associated field-oriented control (FOC) principle, furthermore, three control laws are designed and implemented on the DFIG model. Simulation results discuss the WECS performances in different operating modes for each established control law. Conclusions and perspectives are given at the end.

\section{Description of WECS based on the DFIG topology}

DFIG topology for variable speed wind turbines depends basically on the conventional control scheme that is shown in Fig. 2. The GSC is generally configured to control the DC link voltage and the power factor on the grid side, regardless of the operating mode of the DFIG, while the purpose of having the converter on the rotor side of the DFIG is to control the stator powers of the machine. The power supplied to the DFG rotor is provided by the two bidirectional converters in order to exchange the power from and to the grid. This structure uses two cascaded voltage inverters equipped with IGBTs and linked through a DC link with a capacitor filter between them [16].

The speed and power control are carried out in two overlapping loops. Indeed, the reference of the quadrature component of the current $I_{q r}$ comes from the regulation of the speed, while the component $I_{d r}$ mainly fixes the power factor to the stator. When the rotational speed is greater than the synchronous speed, the slip and the slip power become negative. In other words, the converter absorbs the power of the rotor to inject it into the power grid according to the hyper-synchronous generator mode. On the other hand, when the rotational speed is lower than the speed of synchronism, the slip, and the power become positive. Thus, the converter injects the power into the rotor according to the hypo-synchronous generator mode. In addition, the machine can work in synchronous mode and behaves exactly like a synchronous machine [15].

The MPPT control loop adapts the generator's functionality according to the operational speed of the wind by adjusting the rotor speed, hence, provide a training torque proportional with the wind speed which in turn is proportional to the active power and therefore to the rotor quadrature current $I_{q r}$ [9].

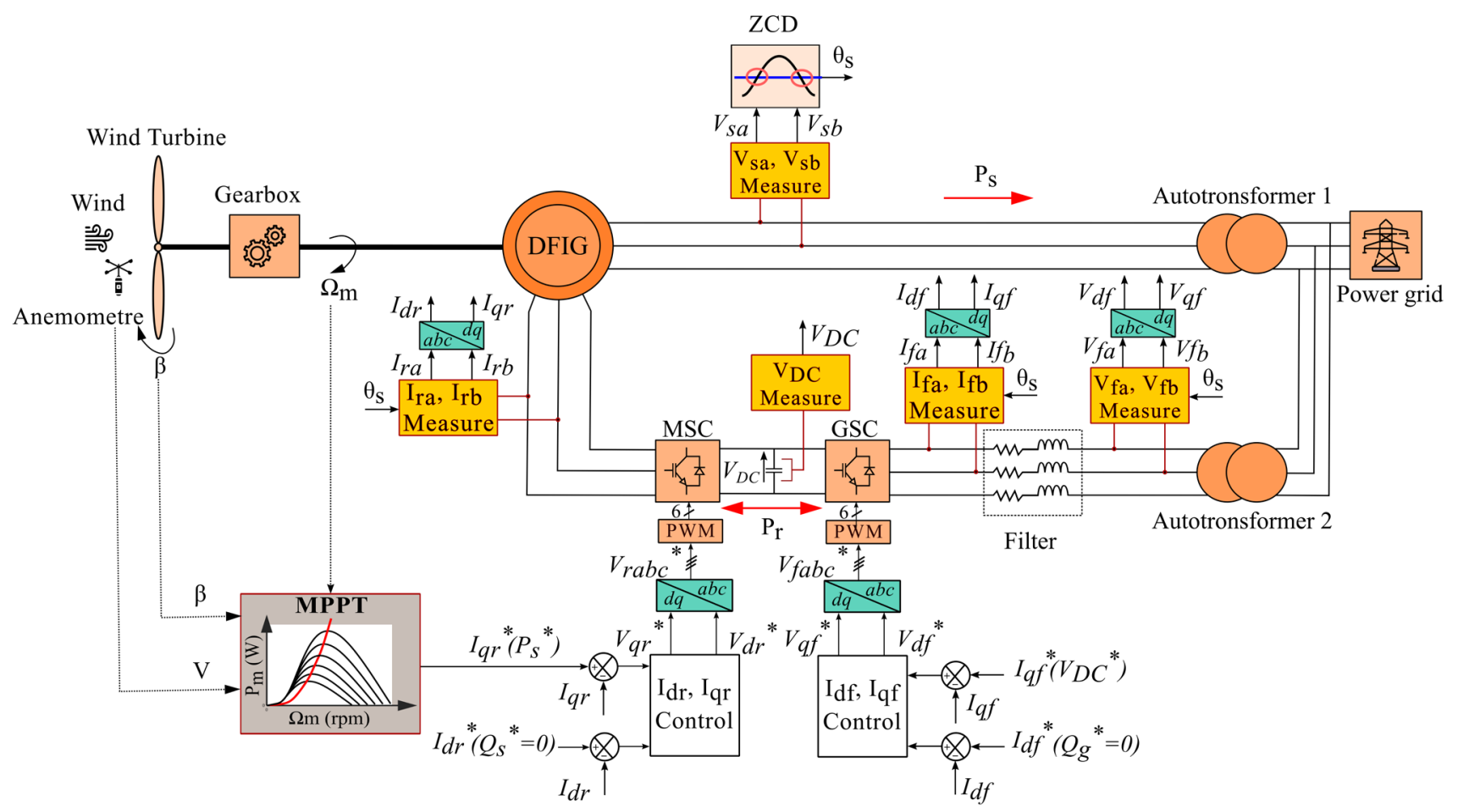

Fig. 2 The conventional control scheme of DFIG with partly rated power converter 
The needed electrical measurements are currents and voltages, which require sensors at a satisfactory cost. The stator voltages $\left(V_{s a}, V_{s b}\right)$ are needed for the synchronization with the power grid, while both rotor dq currents $\left(I_{d r}, I_{q r}\right)$ are measured for the stator active/reactive power $\left(P_{s}, Q_{s}\right)$ dual control loops for the MSC. The GSC needs the DC link voltage measurement VDC and the filter currents estimates $\left(I_{d f}, I_{q f}\right)$ to ensure the bidirectional flow of the active/ reactive power. The speed control loop requires the precise knowledge of rotor position which is provided by an incremental encoder with a top index, while the MPPT loop requires the knowledge of wind speed which can be provided by an anemometer $[3,9,15]$.

\section{Description of the wind turbine model}

The turbine captures the energy of the wind passing through the blades and transforms it into mechanical energy. If the wind turbine is facing the wind, the mechanical power can be expressed by [17]:

$P_{m}=\frac{1}{2} \rho \pi R^{2} V^{3} C_{p}$

where $R(\mathrm{~m})$ is the radius of the blades, $V(\mathrm{~m} / \mathrm{s})$ is the actual wind speed assumed to be measurable and $\lambda$ is the speed ratio between the blade rotation speed and the actual wind speed:

$$
\lambda=\frac{R \Omega_{t}}{V} .
$$

The power coefficient $C_{p}$ characterizes the efficiency of the conversion of wind energy into mechanical energy. This coefficient has a theoretical optimal value of 0.59 (Betz's law), the power coefficient is expressed as a function of the speed ratio $\lambda$ and the pitch angle $\beta$ as follows $[9,18]$ :

$$
\left\{\begin{array}{c}
C_{p}=0.5176\left(\frac{116}{\lambda_{i}}-0.4 \beta-5\right) \exp \left(\frac{-21}{\lambda_{i}}\right)+0.0068 \lambda \\
\frac{1}{\lambda_{i}}=\frac{1}{\lambda+0.08 \beta}-\frac{0.035}{\beta^{3}+1}
\end{array} .\right.
$$

For each given pitch angle $\beta$, the power coefficient $C_{p}$ is strongly influenced by the wind speed $V$ and consequently by the tip speed ratio $\lambda$. In addition, wind fluctuations induce torque fluctuations, increasing the loads on the drive shaft and also affecting the quality of the produced power Fig. 3(b). Therefore, to produce the maximum kinetic energy from the wind, the power coefficient must reach its maximum value Fig. 3(a), hence, the MPPT

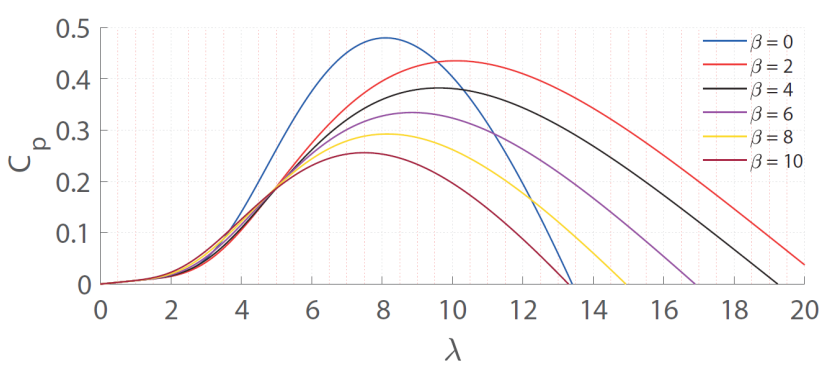

(a)

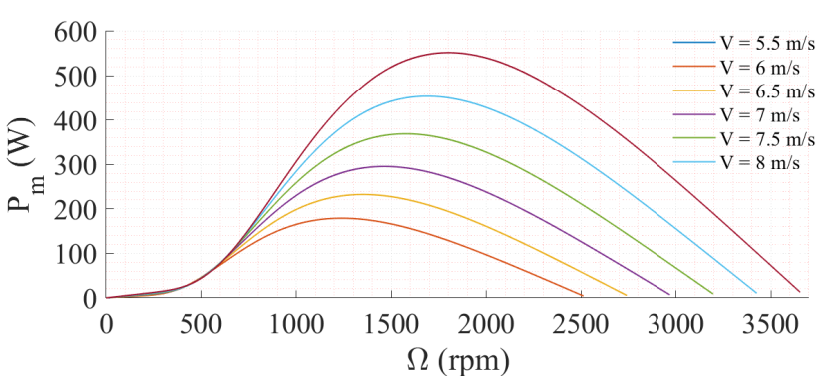

(b)

Fig. 3 Characteristics of the variable speed wind turbine (a) power coefficient (b) aerodynamic power

makes that possible by adapting the rotational speed to the wind speed for an optimum speed ratio $\lambda_{\text {opt }}$ for the actual pitch angle. This is the principle of the variable speed based wind turbine $[15,19]$.

The aerodynamic torque developed by the turbine blades is defined by [16]:

$T_{t}=\frac{1}{2 \Omega_{t}} \rho \pi R^{2} V^{3} C_{p}$

Usually, the simplified two-mass model is the most used in the literature to represent the forces applied to the transmission drive train of the WPS. This model essentially presents the opposite forces applied by the aerodynamic torque $T_{t}$ and the electromagnetic torque $T_{m}$ on the shaft passing through the gearbox Fig. 4 [20, 21].

The dynamics of the low-speed shaft can be described by:

$J_{t} \frac{d \Omega_{t}}{d t}=T_{t}-f_{t} \Omega_{t}-T_{L s}$

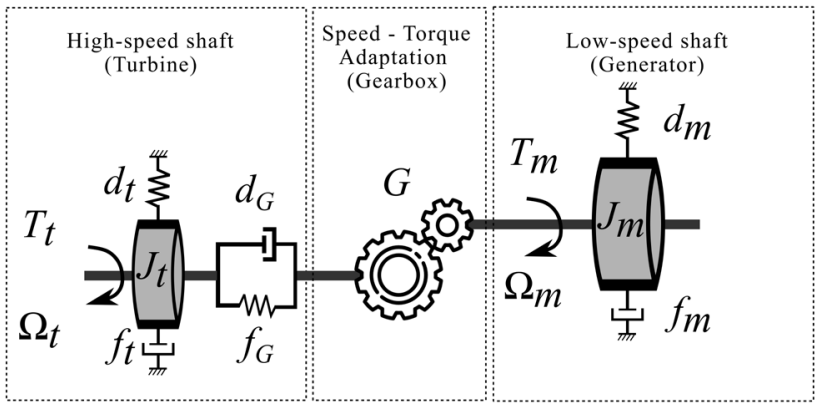

Fig. 4 Two mass schematic model of WPS drive train 
As well as the dynamics of the high-speed shaft can be expressed by:

$J_{g} \frac{d \Omega_{m}}{d t}=T_{H s}-f_{m} \Omega_{m}-T_{m}$,

where $\Omega_{m}$ and $\Omega_{t}$ represents the mechanical high-speed shaft respectively, $T_{L s}$ is the torque of the low-speed shaft and $T_{H s}$ is the torque of the high-speed shaft. The total inertia of the mechanical part $J_{t}$ represents around $90 \%$ of the entire inertia of the WPS, the inertia of the generator noted $J_{g}$ being assumed to be low regarding $J_{t}$. The viscous frictions and the stiffness coefficients are noted by the coefficients $f_{t}, d_{t}$ for the turbine, and $f_{m}$ and $d_{m}$ for the generator. Gearbox having a coefficient of stiffness $d_{G}$ and a coefficient of damping $f_{G}$. However, the stiffness coefficients $d_{G}$, $d_{t}$ and $d_{m}$ are generally low, so they can be neglected [12]. Hence, torque equations are:

$\left\{\begin{array}{l}\frac{d T_{L s}}{d t}=d_{G}\left(\Omega_{t}-\Omega_{m}\right)+f_{G}\left(\frac{d \Omega_{t}}{d t}-\frac{d \Omega_{m}}{d t}\right) \\ \frac{d T_{H s}}{d t}=d_{G}\left(\Omega_{m}-\Omega_{t}\right)+f_{G}\left(\frac{d \Omega_{m}}{d t}-\frac{d \Omega_{t}}{d t}\right)\end{array}\right.$.

The transmission ratio $G$ for an ideal gearbox is given by [2]:

$G=\frac{T_{L s}}{T_{H s}}=\frac{\Omega_{m}}{\Omega_{t}}$

The total WPS inertia can be expressed by:

$J=\frac{J_{t}}{G^{2}}+J_{m}$.

The overall wind turbine model, including its both static-dynamic parts, is given in Fig. 5 [22].

The operating range of the variable speed wind turbine can be divided into three basic regions as shown Fig. 6 [2, 13].

Wind Turbine Operation Around Cut-In Speed: Phase 1 (O-A): In this part, the wind system has not yet connected to the electrical grid, because the wind speed has not yet reached the cut-in speed $\left(V<V_{\min }\right)$ that allows the production of mechanical power $\left(P_{m}=0\right)$, the system stays

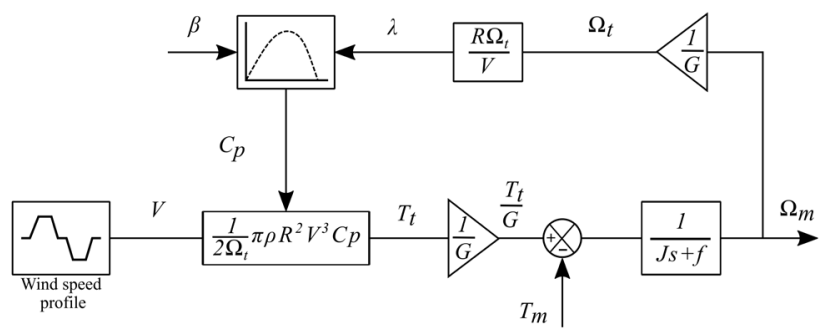

Fig. 5 The overall model of a variable-speed WPS

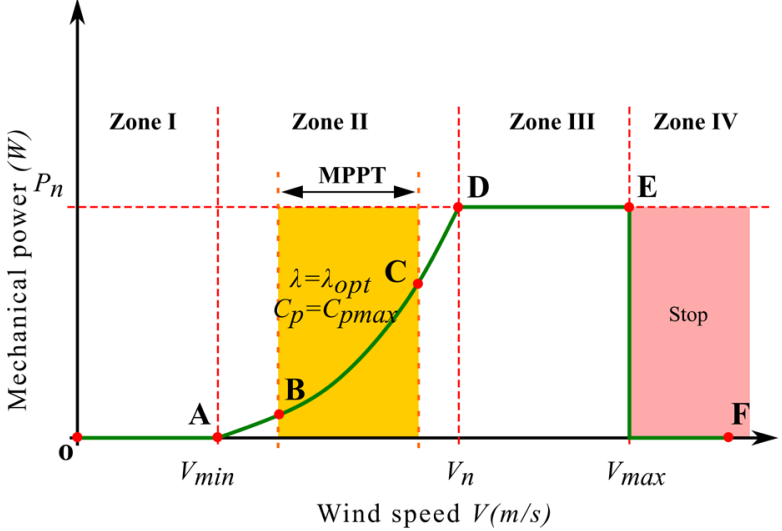

Fig. 6 The operational range of a variable speed based WPS

in standby mode by keeping a minimum rotor rotational speed until wind speed increases.

Phase 2 (A-B): The system can be connected to the grid because the wind speed is higher than the cut-in speed $\left(V>V_{\min }\right)$ and produces low mechanical energy according while keeping a minimum rotor rotational speed because the $C_{\text {pmax }}$ has not yet reached. MPPT Operation of Wind Turbine: The MPPT in phase $3(\mathrm{~B}-\mathrm{C})$ has the role of maintaining $C_{p}$ at its maximum value $\left(C_{p}=C_{p \max }\right)$ by adjusting the rotor rotational speed according to the wind speed change. Hence, the tip speed ratio keeps its optimum value $\left(\lambda=\lambda_{\text {opt }}\right)$ [23] (Fig. 7).

In this phase, the wind turbine is controlled at the optimum turbine rotational speed for each captured wind speed,

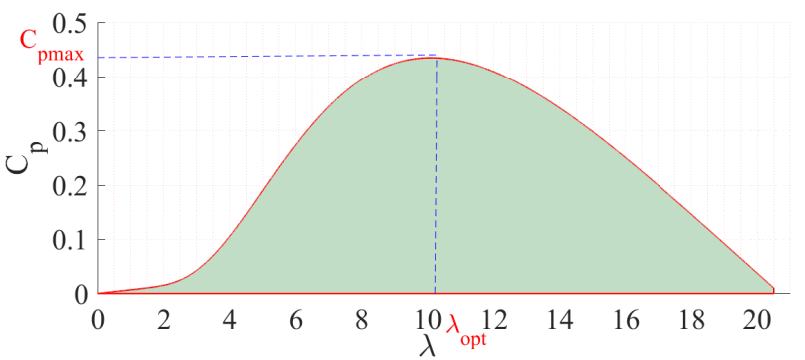

(a)

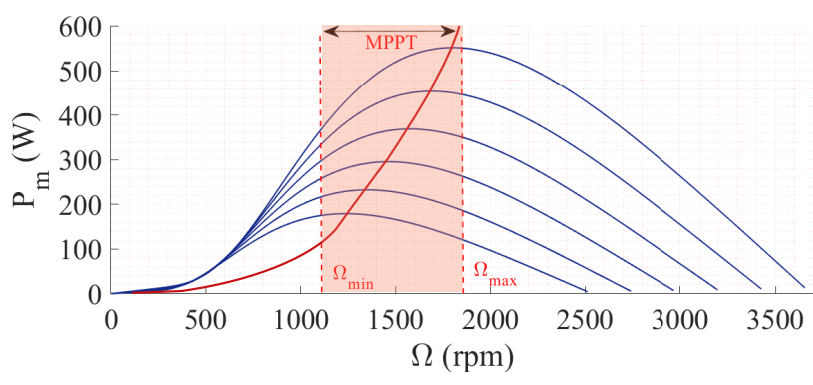

(b)

Fig. 7 Principle of the MPPT operation (a) maximum power coefficient (b) available aerodynamic power 
hence, the generated electromagnetic torque become linked into this speed, consequently, the quadrature rotor current of the generator $I_{q r}$. Fig. 8 illustrates the overall diagram which explains the operating principle of MPPT $[11,24]$.

The TSR based MPPT strategy consists of keeping the speed ratio at its optimum value which corresponds to the maximum value of the power coefficient by adjusting the rotor rotational speed. The mechanical speed is expressed by [25]:

$$
\Omega_{m}^{*}=G \frac{V \lambda_{o p t}}{R} .
$$

Wind Turbine Operation Around Cut-off Speed: Phase 4 (C-D): The wind turbine reaches the rated rotational speed. Therefore, the rotor speed is controlled for this constant rated value to avoid excessive noise and mechanical stress on the wind turbine. The tip speed ratio is not optimum and the power coefficient is lower than $C_{\text {pmax }}$ value.

Phase 5 (D-E): The wind turbine operates for a wind speed beyond the nominal speed $V_{n}$ and lower than $V_{\max }$ $\left(V_{\min }<V<V_{\max }\right)$. Thus, the mechanical power is fixed at the rated value to avoid mechanical overload, as well as overcurrent in the power converters. The power output is controlled by adjusting the pitch angle.

Phase 6 (E-F): When the wind speed becomes very high $\left(V>V_{\max }\right)$, the system stops power production to avoid mechanical and electrical damage.

\section{DFIG Modeling and control}

\subsection{DFIG Simplified model}

The DFIG modeling is identical to that of the induction machine, the only difference lies in the fact that the rotor windings are not short-circuited, which means that the rotor voltages are not zero [26]. The mathematical model is obtained using the Park transformation. Fig. 9 presents the equivalent circuit of a DFIG in the $d q$ reference frame [2].

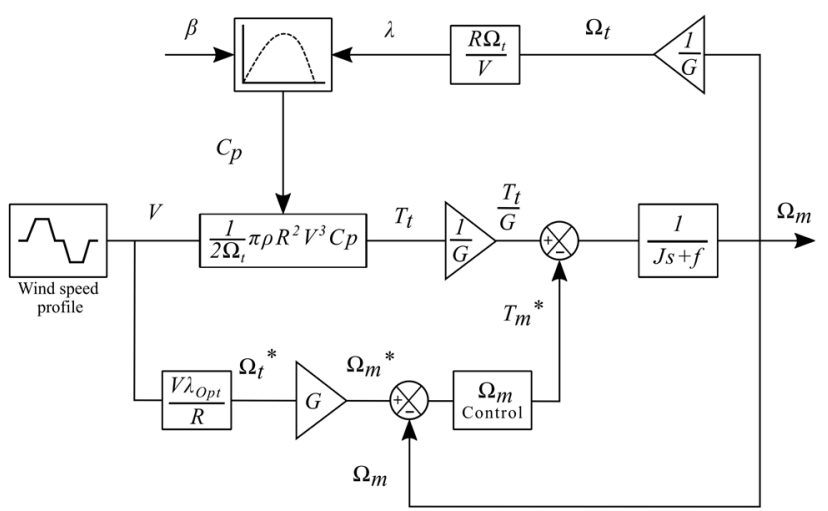

Fig. 8 Principle of the TSR based MPPT algorithm

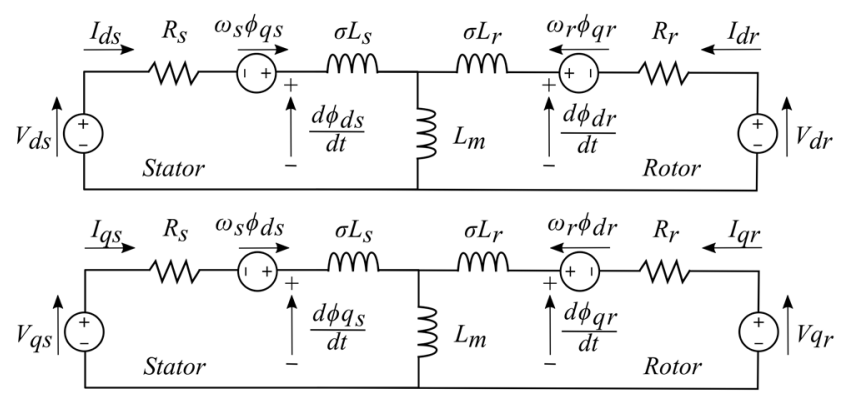

Fig. 9 DFIG equivalent circuit

\subsection{DFIG Field oriented control}

The purpose of vector control is to manage the induction motor as a DC motor with independent excitation where there is a natural decoupling between the component responsible for the control of the flux (the excitation current) and the one linked to the torque (the armature current). However, instead of decoupling the flux from the electromagnetic torque, the purpose of DFIG control is to independently control the active and reactive stator power. In this perspective, we use the stator flux orientation to highlight the relation between the stator powers and the rotor voltages generated by the rotor side inverter [27]. The two components of the flux become [11]:

$\left\{\begin{array}{c}\varphi_{d s}=\varphi_{s} \\ \varphi_{q s}=0\end{array}\right.$.

Consequently, the expression of the electromagnetic torque becomes [28]:

$$
T_{e m}=-p \frac{M}{L_{s}} \varphi_{s} I_{q r} .
$$

Furthermore, the decoupled active and reactive stator powers formulas become $[3,9]$ :

$\left\{\begin{array}{c}P_{s}=-\frac{M V_{s}}{L_{s}} I_{q r}+\frac{\varphi_{s}}{L_{s}} \\ Q_{s}=-\frac{M V_{s}}{L_{s}} I_{d r}+\frac{V_{s}^{2}}{\omega_{s} L_{s}}\end{array}\right.$.

We notice that the active power becomes dependent only on the quadrature component of the rotor current $I_{q r}$, while the reactive power is dependent on the direct component of the rotor current $I_{d r}$. In order to achieve control, the expression of the control voltages must be expressed as a function of rotor currents [2]:

$$
\left\{\begin{array}{l}
V_{d r}=R_{r} I_{d r}+\sigma L_{r} \frac{d I_{d r}}{d t}-\sigma L_{r} \omega_{r} I_{q r} \\
V_{q r}=R_{r} I_{q r}+\sigma L_{r} \frac{d I_{q r}}{d t}+\sigma L_{r} \omega_{r} I_{d r}+\omega_{r} \frac{M V_{s}}{\omega_{s} L_{s}}
\end{array} .\right.
$$


The internal simplified model of the machine can be translated into a block diagram as shown in Fig. 10 [28].

\section{DFIG Direct power control DPC}

The principle of the DFIG direct power control is based on the direct action on the active and reactive stator powers by adjusting the rotor currents. This method consists in neglecting the coupling terms between the $d$ and $q$ axes. This is allowed thanks to the FOC. Thus, each axis can control power instantly and independently of the other with its own current controller. Hence, the $q$-axis rotor current component acts on the control of the active power, and the $d$-axis component controls the reactive power [29].

\subsection{PI controller DPC synthesis}

Given to the decoupling model of the DFIG and its linearity, a linear PI controller can adequately achieve direct power control. It is possible to eliminate the static error between the reference value and the measured one, thanks to its integral action. A derivative action has the role of anticipating and accelerating the response, therefore it can amplify the system noises [3]. We will not use a PID controller for this purpose (Fig. 11).

The dimensioning of the PI controller parameters is defined by the pole compensation method. Accordingly, the $k_{p}$ and $k_{i}$ gains are then expressed as a function of the chosen response time and of the parameters of the machine. However, the implementation is a little different from the linear case because we have to implement a specific anti-windup procedure which consist of blocking the numerical integration of the error whenever the output reaches it saturation level. This ensures a fast recovery of

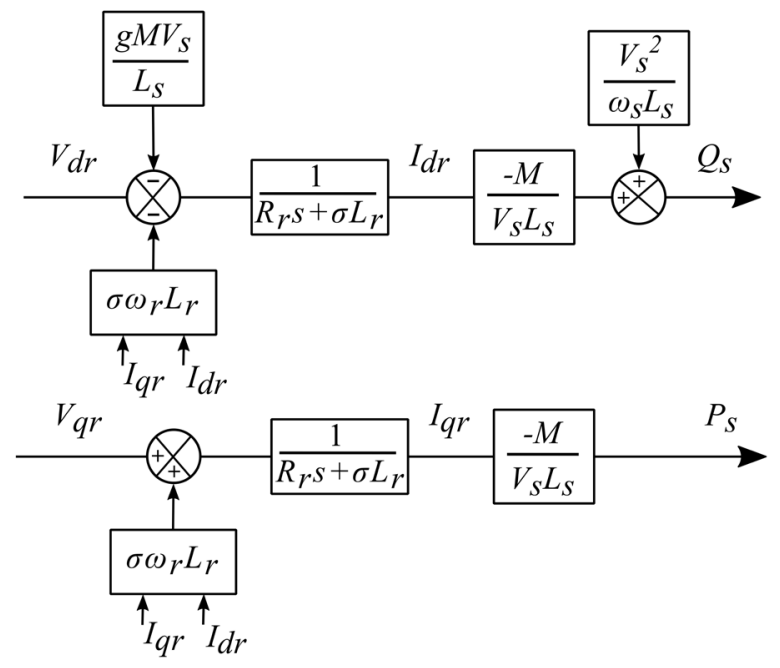

Fig. 10 Block diagram of the DFIG simplified model the control without changing the performances on small reference variation and disturbance rejection.

\subsection{First-order sliding mode DPC synthesis}

The idea behind SMC is to choose a sliding surface along which the system can slide to its desired final value. We bring the evolving state trajectory of the system towards the sliding surface (hyperplane) Fig. 12. Then, we use an appropriate switching logic around the sliding surface until the point of equilibrium [30].

We replace the linear PI by the SMC nonlinear controller. Therefore, the sliding surfaces of active and reactive power $\left(P_{s}, Q_{s}\right)$ are defined as function of the tracking errors of the rotor current components $\left(I_{q r}, I_{d r}\right)$ respectively for a relative degree by [7]:

$S\left(I_{d q r}\right)=\left(I_{d q r}{ }^{*}-I_{d q r}\right)$.

Thus, we consider the following Lyapunov function:

$V\left(S_{I_{d q r}}\right)=\frac{1}{2} S_{I_{d q r}}^{2}$.

The derivative of the Lyapunov function is:

$\dot{V}\left(S_{I_{d q r}}\right)=S_{I_{d q r}} S_{I_{d q r}}$.

By replacing the expression of the derivative of the currents $\left(I_{q r}, I_{d r}\right)$ in the equations of the rotor voltages $\left(V_{q r}, V_{d r}\right)$, we obtain:

$\left\{\begin{array}{l}\dot{S_{I_{q r}}}=\dot{I_{q r}}{ }^{*}-\frac{1}{\sigma L_{r}}\left(V_{q r}-R_{r} I_{q r}-\sigma L_{r} \omega_{r} I_{d r}-\omega_{r} \frac{M V_{s}}{\omega_{s} L_{s}}\right) \\ \dot{S_{I_{d r}}}=\dot{I}_{d r}{ }^{*}-\frac{1}{\sigma L_{r}}\left(V_{d r}-R_{r} I_{d r}+\sigma L_{r} \omega_{r} I_{q r}\right)\end{array}\right.$

In steady state, we have:

$\left\{\begin{array}{l}S\left(I_{q r}\right)=0 ; \dot{S}\left(I_{q r}\right)=0 ; V_{q r}^{d}=0 \\ S\left(I_{d r}\right)=0 ; \dot{S}\left(I_{d r}\right)=0 ; V_{d r}^{d}=0\end{array}\right.$.

Thus, the equivalent control law is expressed by:

$$
\left\{\begin{array}{l}
V_{q r}^{e q}=\sigma L_{r}\left(\dot{I_{q r}}{ }^{*}+\frac{R_{r}}{\sigma L_{r}} I_{q r}+\omega_{r} I_{d r}+\omega_{r} \frac{M V_{s}}{\omega_{s} L_{s}}\right) \\
V_{d r}^{e q}=\sigma L_{r}\left(\dot{I}_{d r}^{*}+\frac{R_{r}}{\sigma L_{r}} I_{d r}-\omega_{r} I_{q r}\right)
\end{array} .\right.
$$

To ensure the convergence of the Lyapunov function, we assume the following discontinuous law function: 


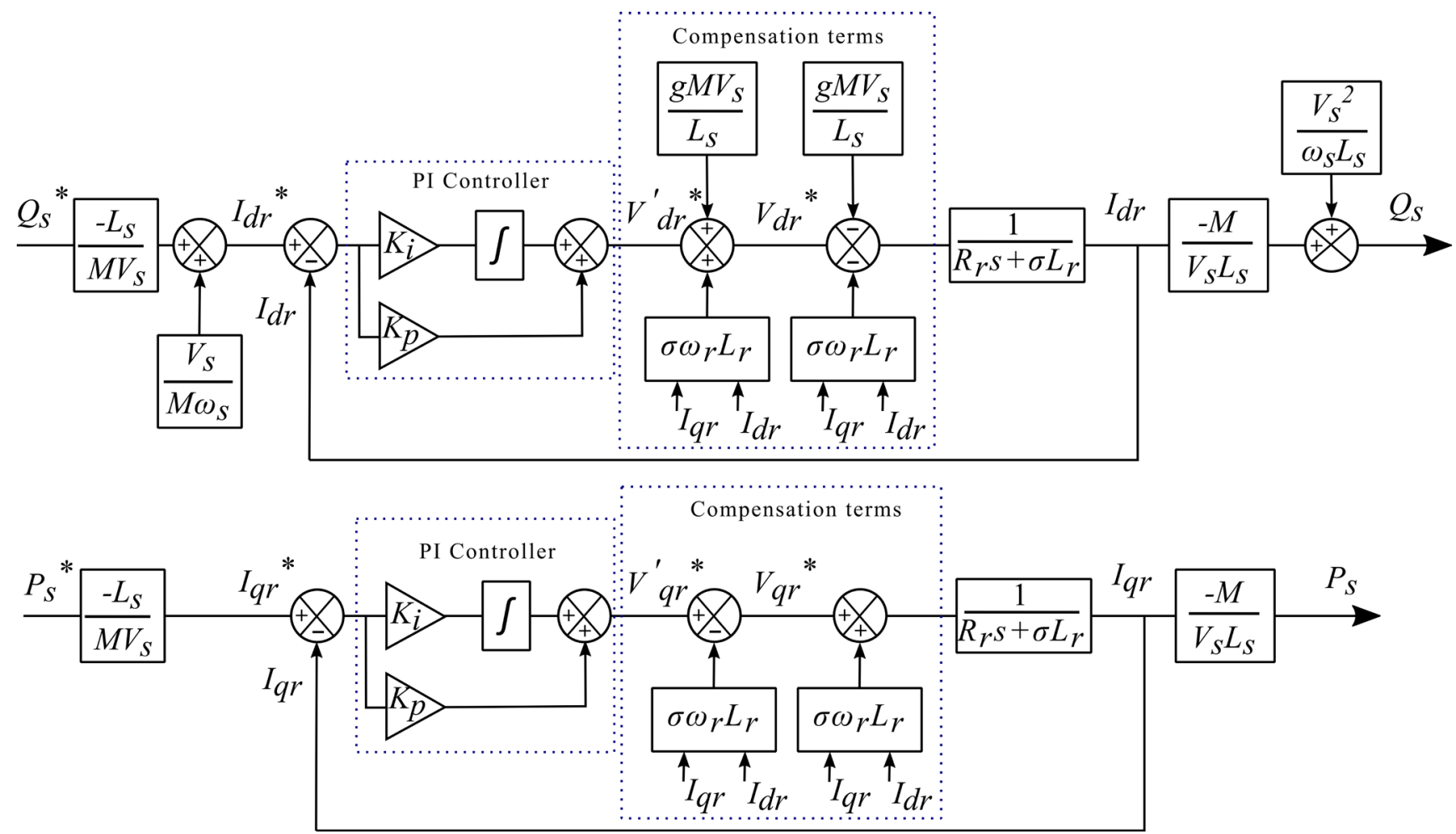

Fig. 11 Diagram of the DFIG direct power control using PI controllers with the addition of the compensation terms

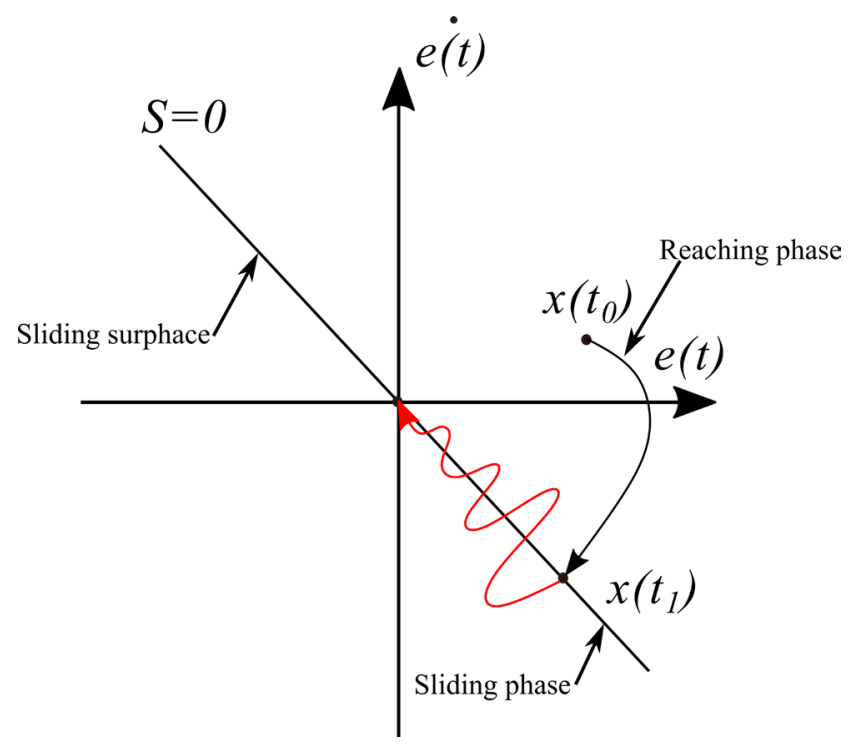

Fig. 12 Principle of Sliding Mode Control

$$
\left\{\begin{array}{l}
V_{q r}^{d}=K_{I_{q r}} \operatorname{Sign}\left(S\left(I_{q r}\right)\right) \\
V_{d r}^{d}=K_{I_{d r}} \operatorname{Sign}\left(S\left(I_{d r}\right)\right)
\end{array} .\right.
$$

Finally, the total control laws are determined by [8]:

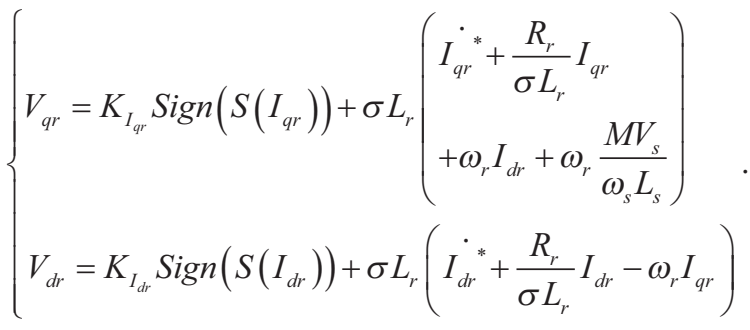

Fig. 13 shows the overall block diagram of the direct power control of the DFIG by sliding control law applied to the grid side inverter [31].

\subsection{High order sliding mode control of DFIG}

The super-twisting algorithm is a case in the class of second-order sliding mode control. It can be applied directly when the system is of first-order relative degree. This technique acts on the higher-order time derivatives of the sliding manifold, and its advantage lies in the reduction of the chattering problem, due to the discontinuity of the control signal [32]. Considering a nonlinear system, generally described by:

$\left\{\begin{array}{l}\dot{x}(t)=f(x, t)+g(x, t) U(t) \\ y=C x\end{array}\right.$.

The super-twisting algorithm defines the control law $U(t)$ as a combination of two terms, algebraic (non-dynamic) term $U_{1}(t)$ and an integral term $U_{2}(t)$, as follow [33]: 


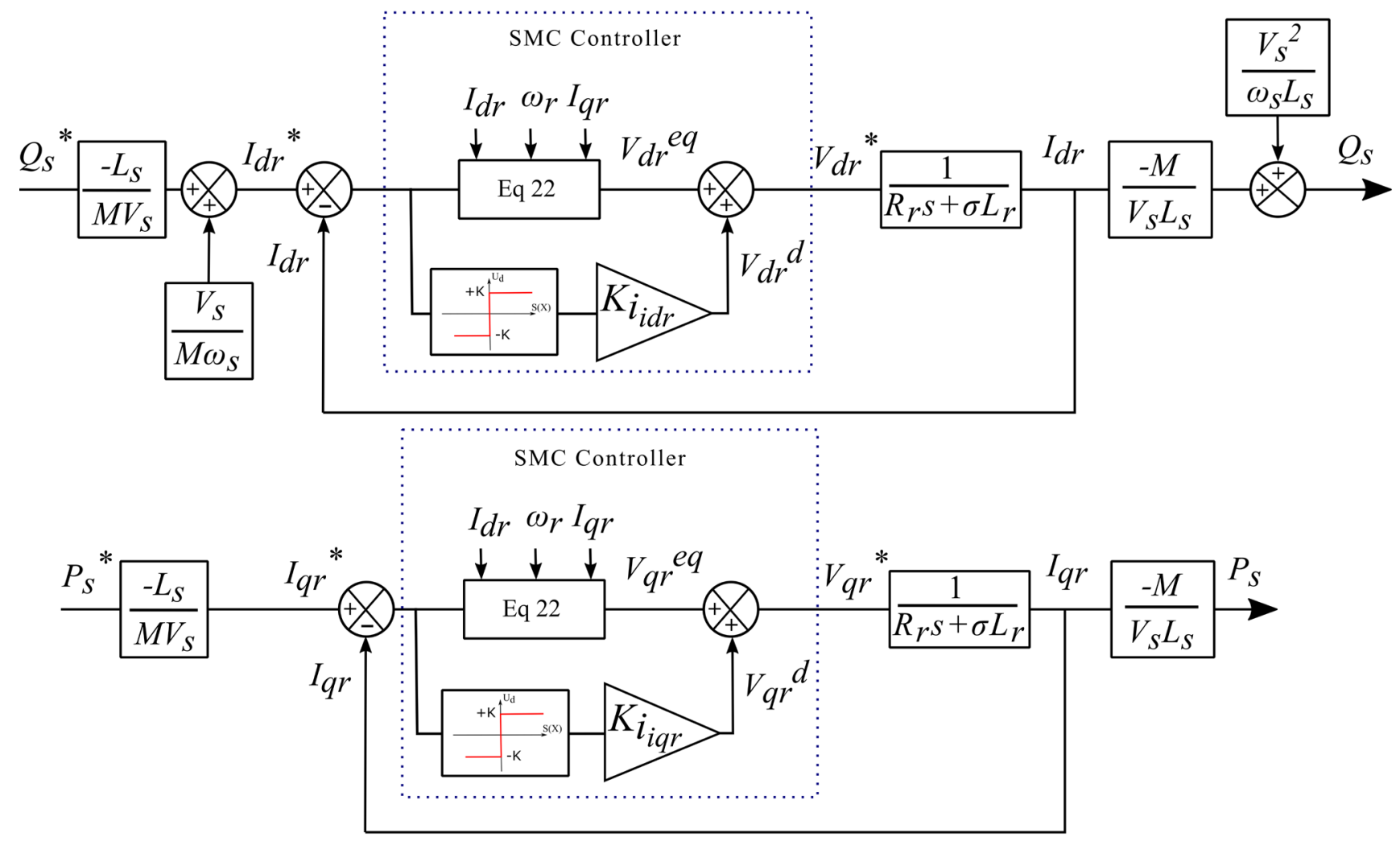

Fig. 13 Diagram of the DFIG direct power control using SMC

$U=U_{1}+U_{2}$,

with:

$U_{1}=\left\{\begin{array}{lr}-U & \text { if }|U|>U_{M} \\ -\alpha \operatorname{Sign}(S) & \text { if not }\end{array}\right.$,

and:

$U_{2}=\left\{\begin{array}{lr}-\lambda\left|S_{0}\right| & \text { if }|U|>S_{0} \\ -\lambda|S|^{\rho} \operatorname{Sign}(s) & \text { if not }\end{array}\right.$,

where $\lambda$ and $\alpha$ are positive gains, $\rho$ is a positive constant $(0<\rho<0.5)$. Assuming the existence of a positive number $\phi$ that satisfies.

$$
|\dot{S}| \leq \phi
$$

The trajectory of the super-twisting algorithm is considered as a spiral around the origin in the phase plane Fig. 14. The trajectory converges at the point of equilibrium $(S, \dot{S})$ in a finite time. The sufficient conditions for finite time convergence are [34]:

$\left\{\begin{array}{c}\alpha>\phi \\ \lambda \geq 2 \sqrt{\phi(\alpha+\phi) /(\alpha-\phi)}\end{array}\right.$

We can simplify the algorithm if $S_{0}=\infty$ :

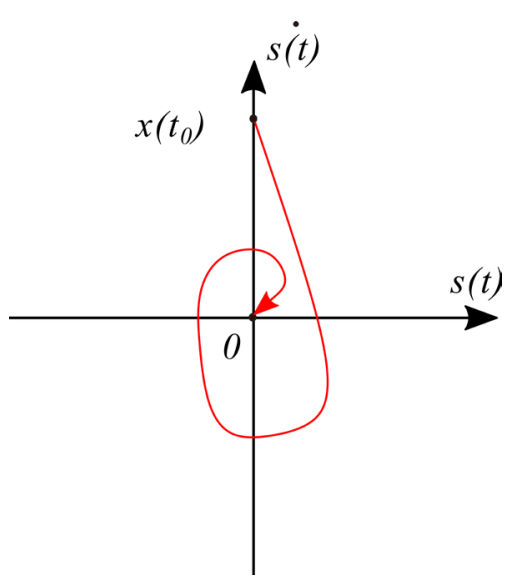

Fig. 14 Convergence of the twisting algorithm in the plane

$\left\{\begin{array}{c}U_{2}=-\lambda|S|^{\rho} \operatorname{Sign}(S)+U_{1} \\ \dot{U}_{1}=-\alpha \operatorname{Sign}(S)\end{array}\right.$.

According to the above, the output reference of the rotor voltage is expressed as [14, 35]:

$\left\{\begin{array}{l}V_{q r}^{*}=-\lambda\left|\left(S_{I_{q r}}\right)\right|^{0.5} \operatorname{Sign}\left(\left(S_{I_{q r}}\right)\right)+\int-\alpha \operatorname{Sign}\left(S_{I_{q r}}\right) d t \\ V_{d r}^{*}=-\lambda\left|\left(S_{I_{d r}}\right)\right|^{0.5} \operatorname{Sign}\left(\left(S_{I_{d r}}\right)\right)+\int-\alpha \operatorname{Sign}\left(S_{I_{d r}}\right) d t\end{array}\right.$. 
The expression of the super twisting output laws does not depend on the value of $(S, \dot{S})$, but only of their signs. Fig. 15 illustrates the block diagram of the super twisting sliding mode approach for the direct power control of the DFIG [36].

\section{TSR based MPPT operation of variable speed wind turbine}

Three types of control techniques are envisaged to control the mechanical speed as a function of the wind speed measured for a fixed pitch angle at 2 degrees.

\subsection{MPPT operation based on PI speed controller}

The electromagnetic torque reference $T_{m}{ }^{*}$ is the PI speed controller output which ensures speed convergence towards its reference. The gains of the PI controller, $K_{p}$ and $K_{i}$, depend mainly on the internal mechanical parameters of the generator (moment of inertia $J$ and viscous friction $f$ ). The linear speed controller is detailed in Fig. 16 [17, 37].

\subsection{MPPT operation based on SMC speed controller}

To eliminate the hyperlink between the gains of the linear PI controller and the internal parameters of the generator, we introduce the sliding mode control SMC technique to control the DFIG mechanical speed [38]. The relative degree of the surface is equal to one, the sliding surface is defined as:

$S\left(\Omega_{m}\right)=\left(\Omega_{m}^{*}-\Omega_{m}\right)$.
The general control law is given by:

$\dot{S}\left(\Omega_{m}\right)=\dot{\Omega}_{m}^{*}-\frac{1}{J}\left(\left(T_{m}^{e q}+T_{m}^{d}\right)-T_{t}-f \Omega\right)$.

In steady state, we have:

$S\left(\Omega_{m}\right)=0 ; \dot{S}\left(\Omega_{m}\right)=0 ; T_{m}^{d}=0$.

Thus, the equivalent switching law will be:

$T_{m}^{e q}=J \dot{\Omega}_{m}^{*}+T_{t}+f \Omega$.

To ensure the convergence of the Lyapunov function, we assume the following discontinuous law function:

$T_{m}^{d}=K_{\Omega_{m}} \operatorname{Sign}\left(S\left(\Omega_{m}\right)\right)$

Finally, the total control law is determined by:

$T_{m}^{*}=K_{\Omega_{m}} \operatorname{Sign}\left(S\left(\Omega_{m}\right)\right)+J \dot{\Omega}_{m}^{*}+T_{t}+f \Omega$.

Fig. 17 shows the overall block diagram of the direct power control of the DFIG by sliding control law applied to the machine side inverter.

\subsection{MPPT operation based on SMC super twisting speed controller}

The chattering phenomenon presents the major drawback for the first order SMC. Accordingly, the high order SMC is developed to weed out this disadvantage, and it doesn't need the model parameters. The algebraic formula of the
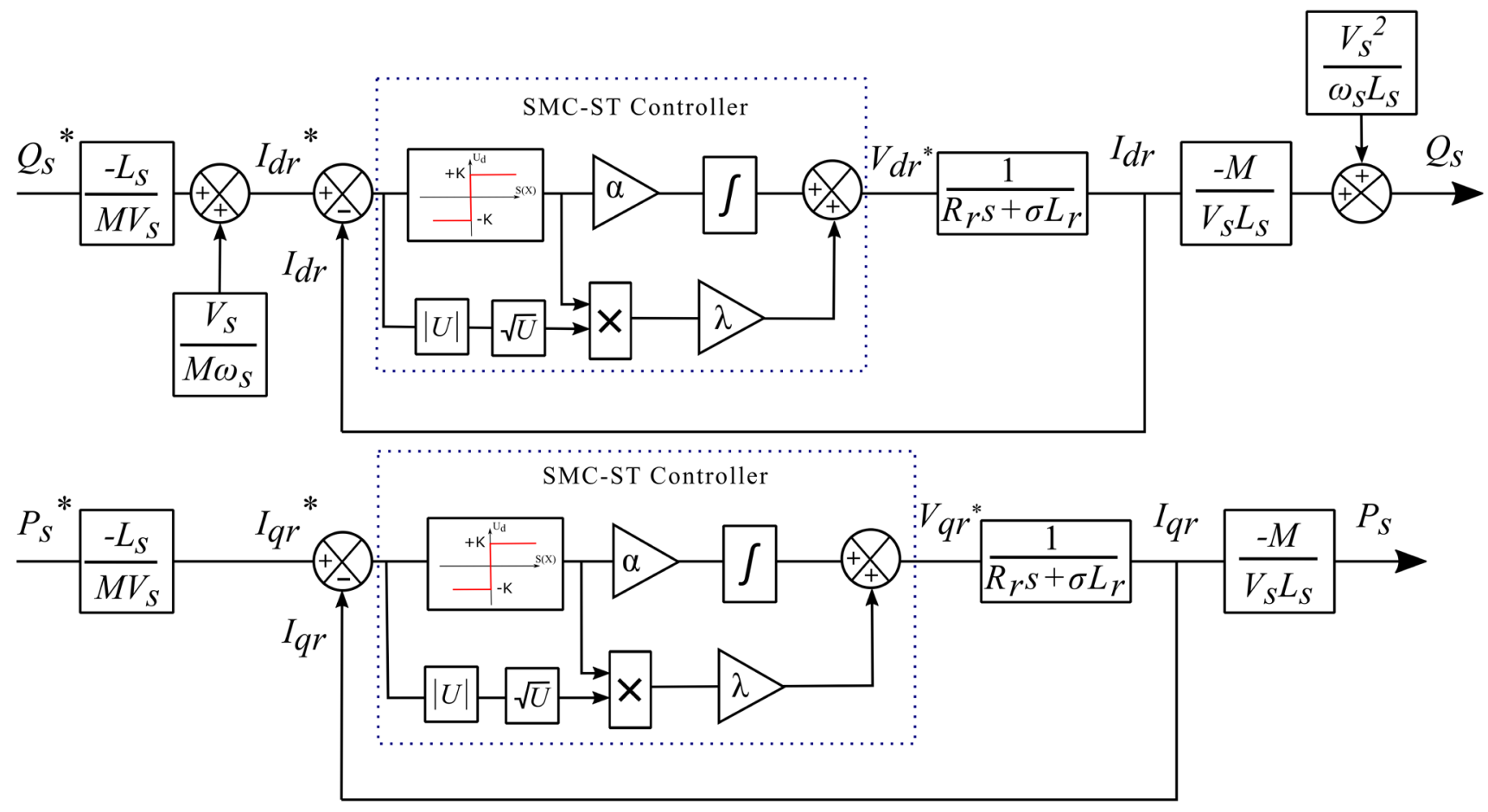

Fig. 15 Diagram of the DFIG direct power control using SMC-ST 


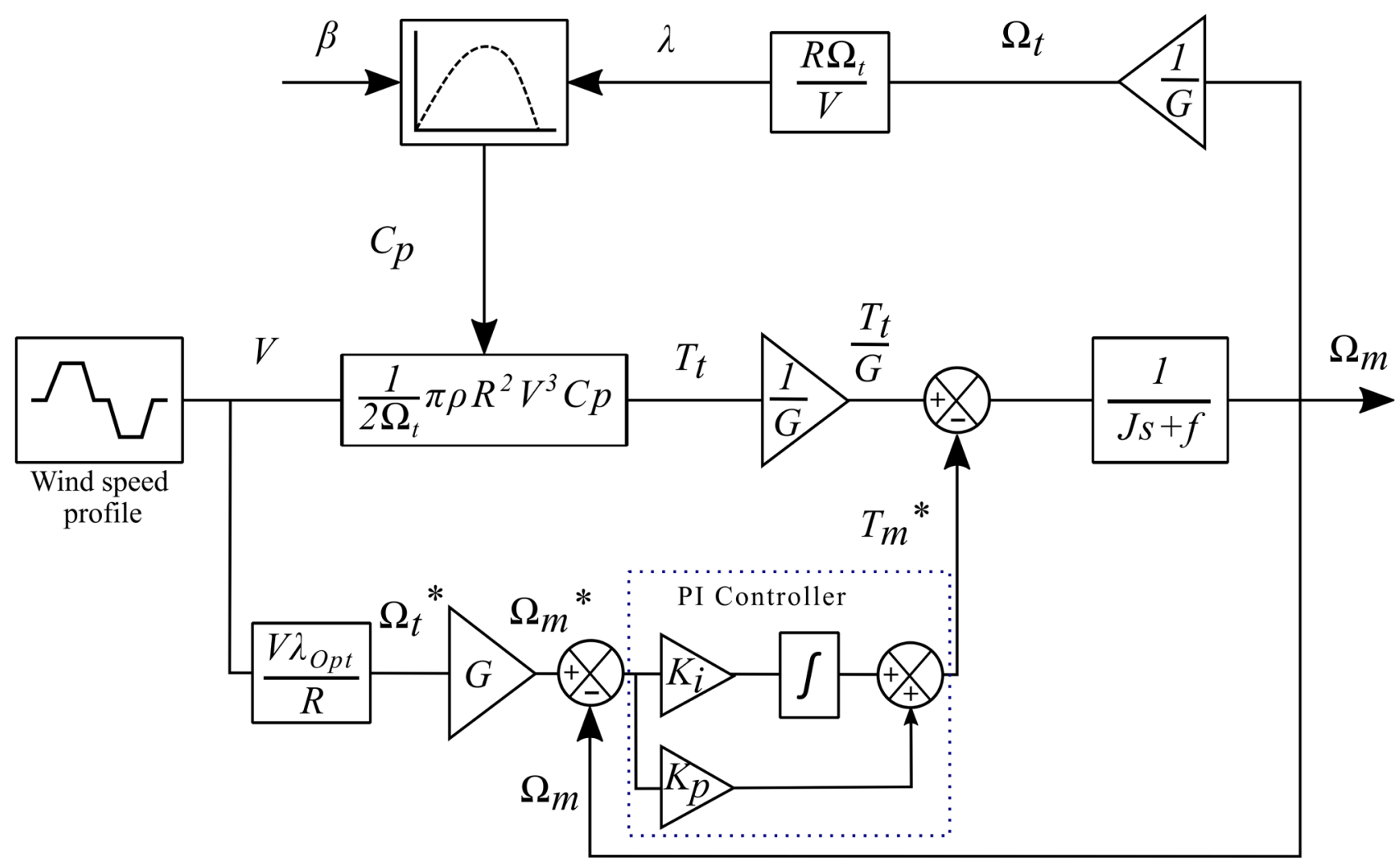

Fig. 16 TSR based MPPT using PI controller
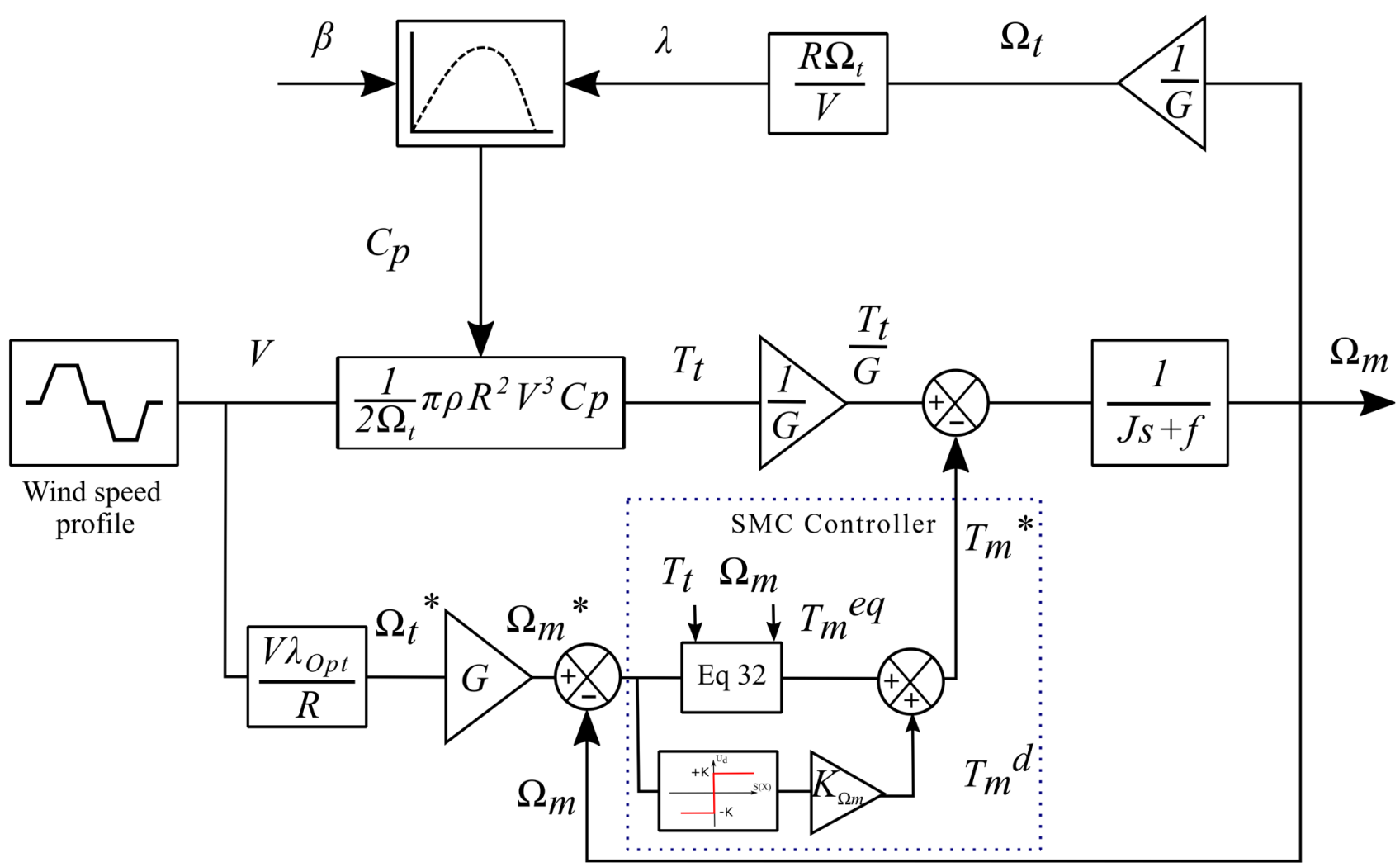

Fig. 17 TSR based MPPT algorithm using SMC controller

mechanical speed SMC super twisting control law has the $\quad T_{m}^{*}=-\lambda\left|\left(S_{\Omega_{m}}\right)\right|^{0.5} \operatorname{Sign}\left(\left(S_{\Omega_{m}}\right)\right)+\int-\alpha \operatorname{Sign}\left(S_{\Omega_{m}}\right)$. following formula [14]: 
The general diagram of the SMC super twist technique of speed control is simplified in Fig. 18.

\subsection{Results and discussions}

To assess the performance of the model and compare the three established controls, we test with a set of simulations under MATLAB / Simulink environment, the DFIG direct power control, as well as the MPPT based speed control. Hence, we use the block diagrams in Fig. 2 to verify the proper functioning of the command applied to the DFIG rotor side converter. We introduce a wind profile reference Fig. 19 that allows the system to operate under zone 2 (BC) including the generator operating modes. The wind reference variation can manage the DFIG operating modes, under hyposynchronous and hypersynchronous modes, around a synchronous speed of $1500 \mathrm{rpm}$ equivalent to a wind speed of $7.5 \mathrm{~m} / \mathrm{s}$. We consider that the grid voltage is ideal, and on the rotor side of the DFIG, the DC bus voltage is considered constant.

The resulting electromagnetic torque has almost the same form as the wind speed curve due to the proportionality between them, thanks to the presence of the MPPT algorithm based on the mechanical speed control loop. The electromagnetic torque Fig. 20 is the output of the
SMC ST controller. It has less mechanical stress compared to the other controllers, thanks to the algebraic nonlinear command law formula.

The mechanical speed is strongly imposed by the torque generated by the controller and depends mainly on the current wind speed, moreover, the mechanical speed alternates between operating modes, crossing the synchronism speed at $1500 \mathrm{rpm}$ (Fig. 21).

A good tracking of the reference speed is obtained by the three speed control strategies Fig 22 (a) and Fig. 23, except for a little disparity for the PI controller while increasing or decreasing the speed. This gives another advantage to nonlinear controllers.

The power coefficient Fig 24 (a) is maintained around its maximum value $C_{\text {pmax }}=0.42$ by the three types of controllers despite variations in the wind, this coefficient is slightly affected when the wind turbine is controlled by the PI type command, he same goes for the tip speed ratio $\lambda$ (Fig 24 (b)), this last remaining stable in its optimum value $\lambda_{\text {opt }}$ at 9 for the three controllers with a negligible effect of the wind variation for the PI.

The obtained results show that the three developed control laws achieve good decoupling, power control, and tracking of the imposed reference values Figs. 25 to 27.

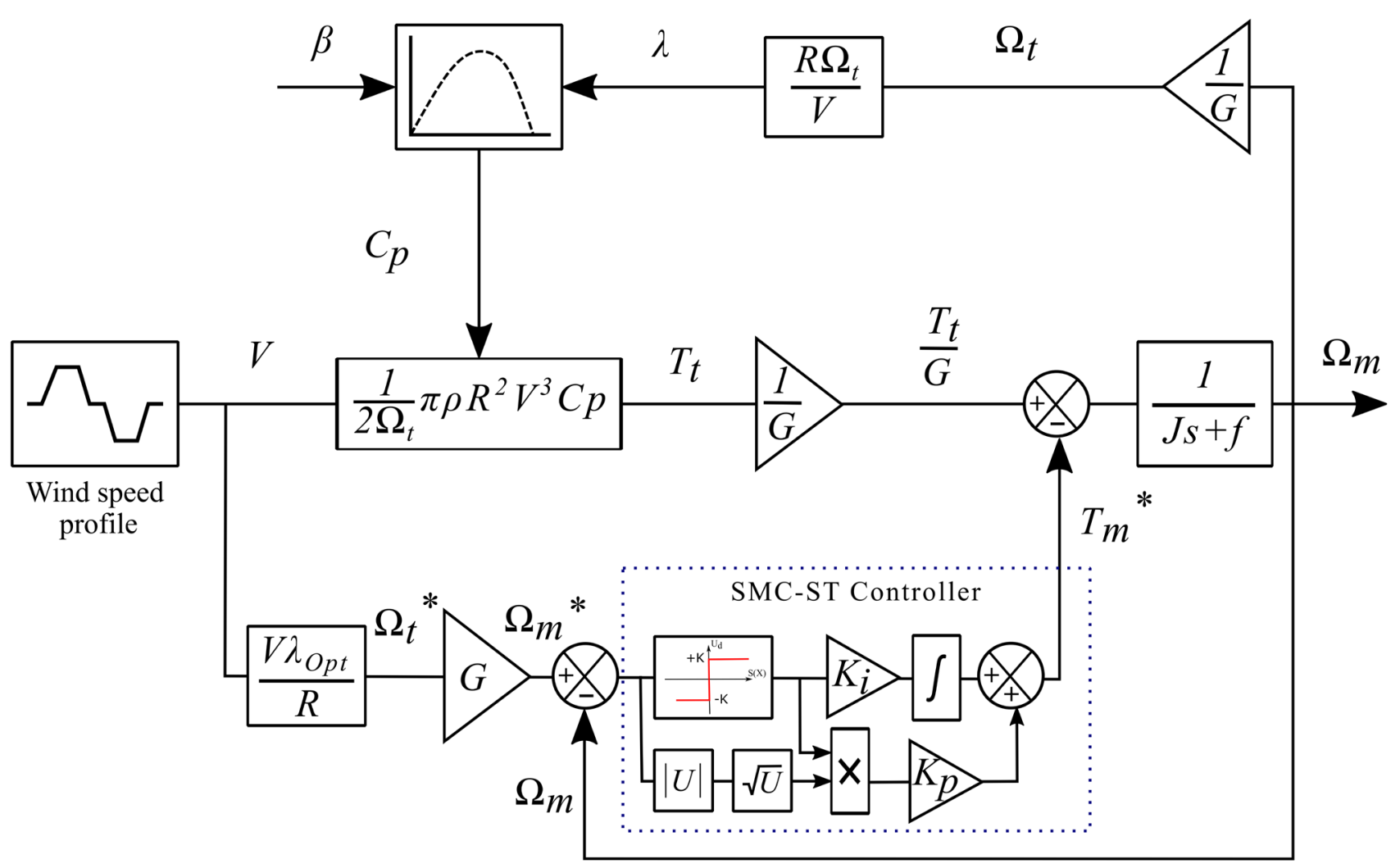

Fig. 18 TSR based MPPT algorithm using SMCST controller 


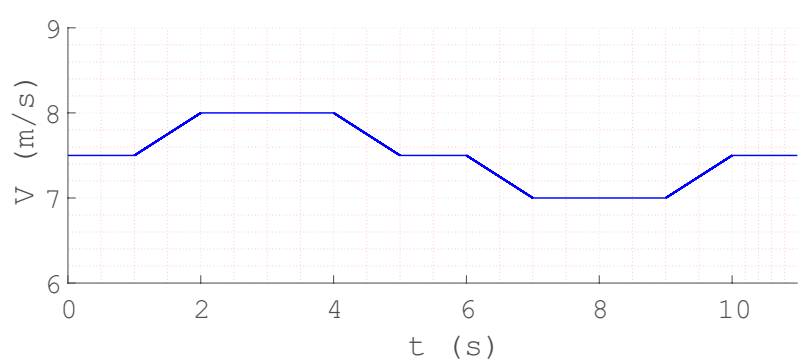

Fig. 19 Wind speed reference variation

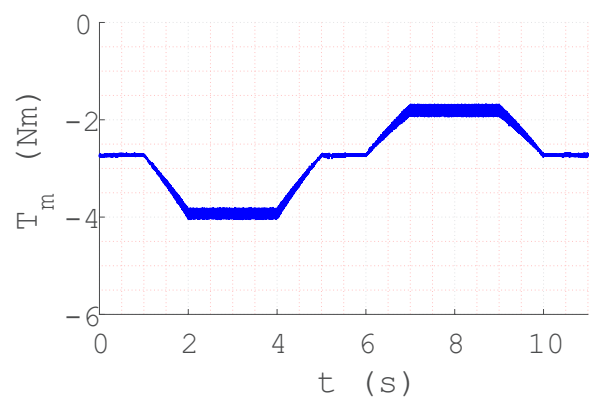

(a)

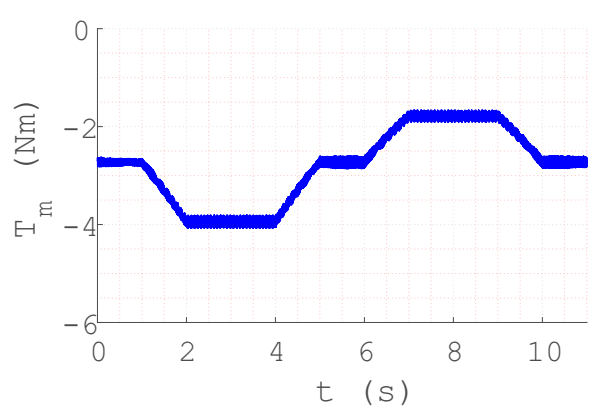

(b)

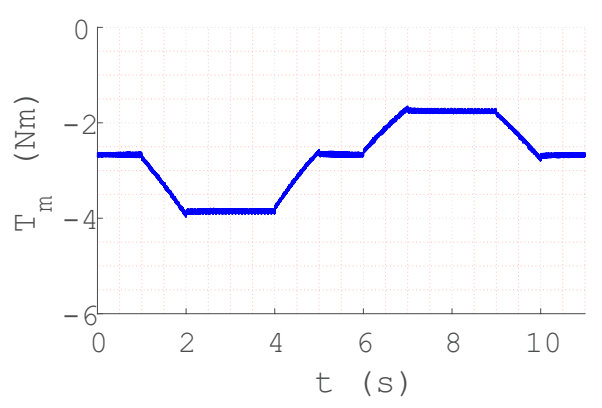

(c)

Fig. 20 DFIG Torque (a) PI (b) SMC (c) ST

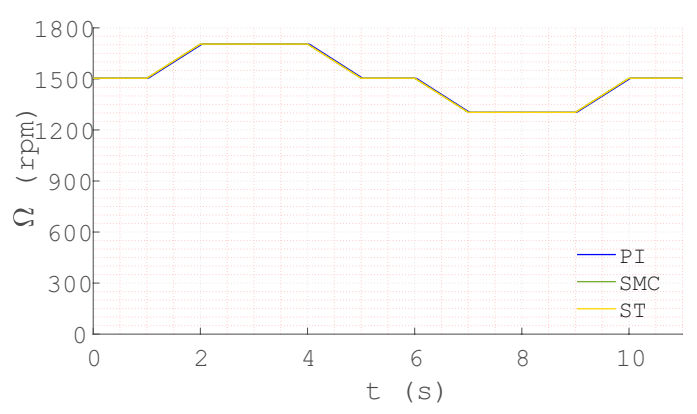

Fig. 21 DFIG mechanical speed

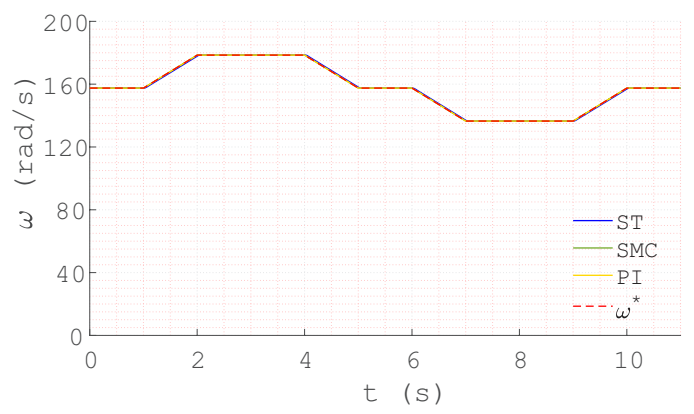

Fig. 22 DFIG speed control

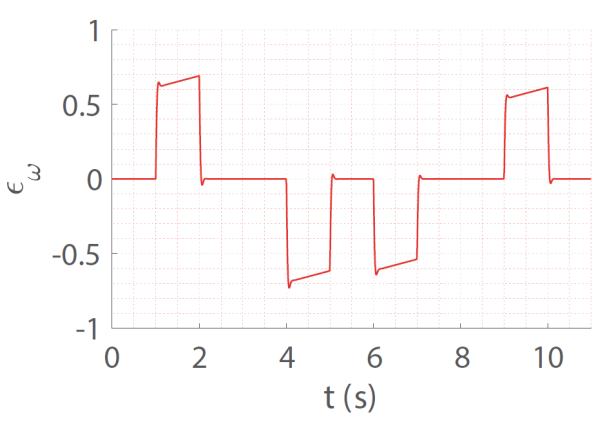

(a)

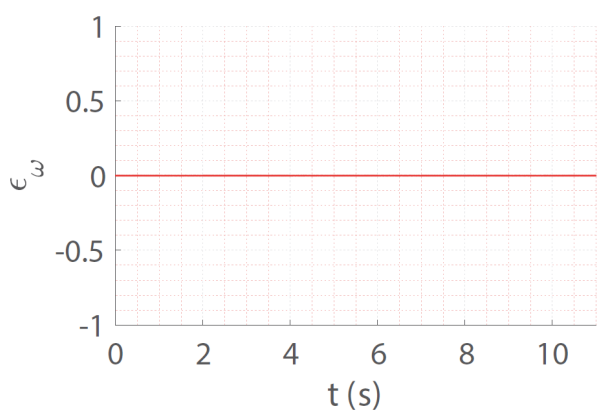

(b)

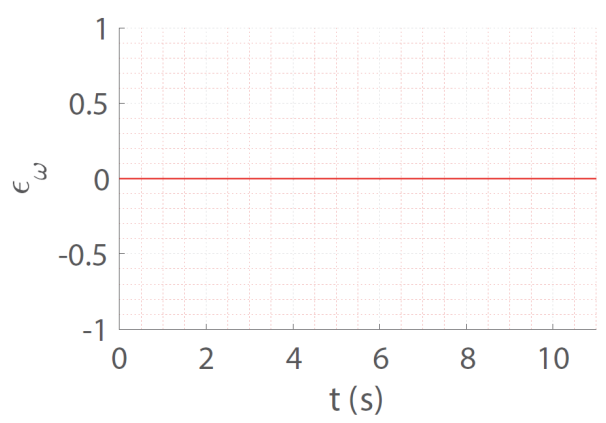

(c)

Fig. 23 Speed tracking error; (a) PI; (b) SMC; (c) ST

The d-axis rotor current reference $I_{d r}{ }^{*}$ is defined to ensure a unity power factor $\left(Q_{s}=0\right.$ Var) on the stator side in order to improve the quality of the energy injected into the grid. Fig. 24 shows a good tracking accuracy between the measured rotor currents $\left(I_{d r}, I_{q r}\right)$ and their references $\left(I_{d r}{ }^{*}, I_{q r}{ }^{*}\right)$, and in consequence, the estimated stator powers $\left(P_{s}, Q_{s}\right)$ and that of references $\left(P_{s}^{*}, Q_{s}^{*}\right)$. There is no notable mutual 


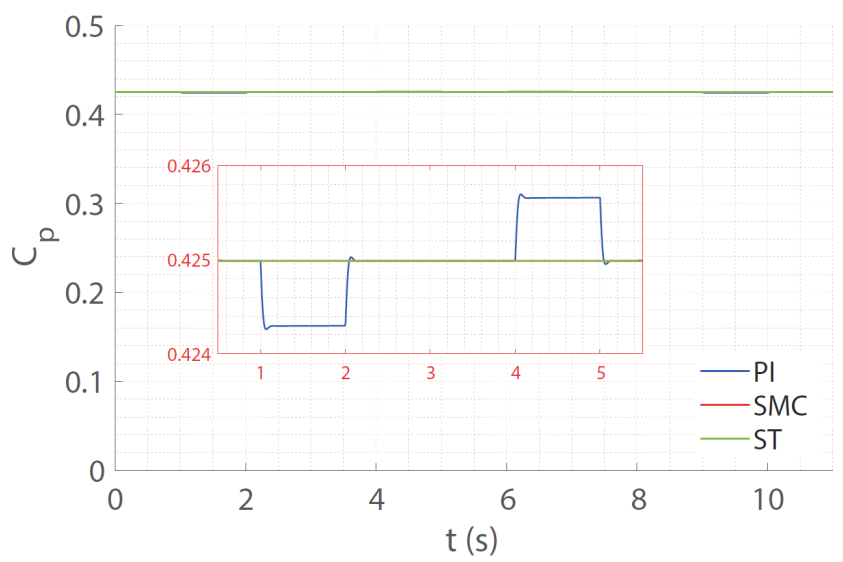

(a)

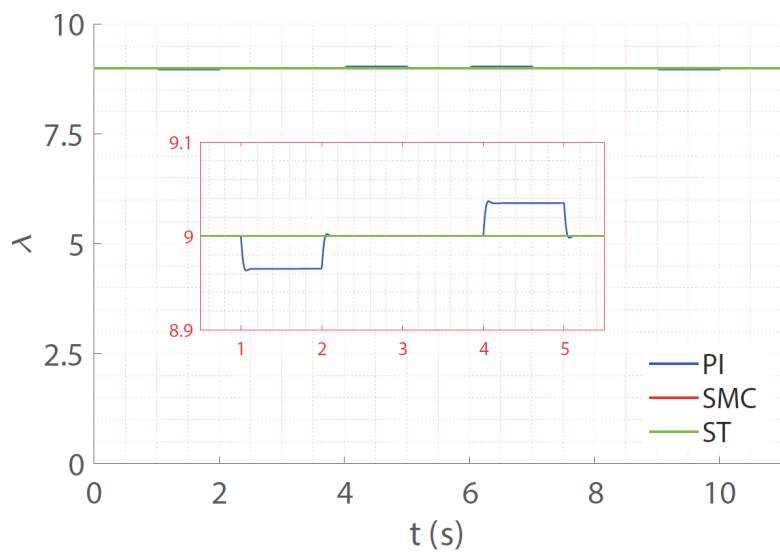

(b)

Fig. 24 (a) Power coefficient (b) Tip speed ratio

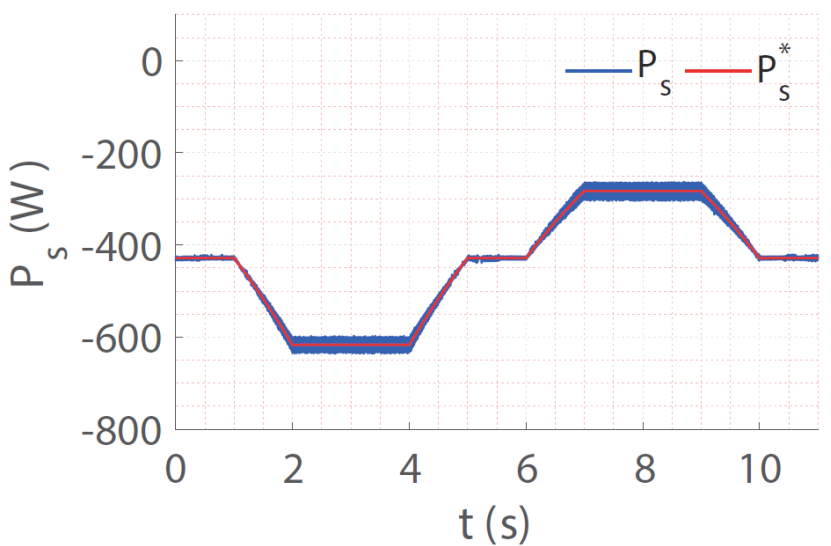

(a)

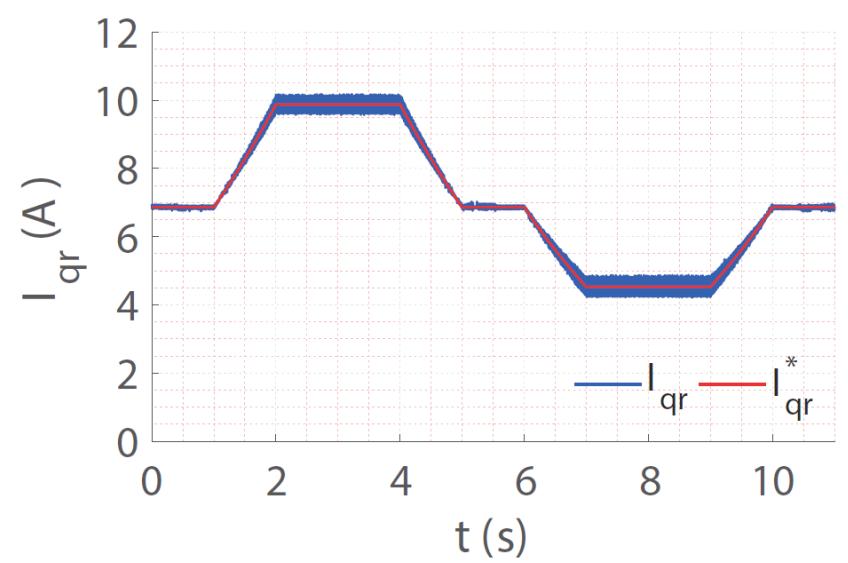

(c)

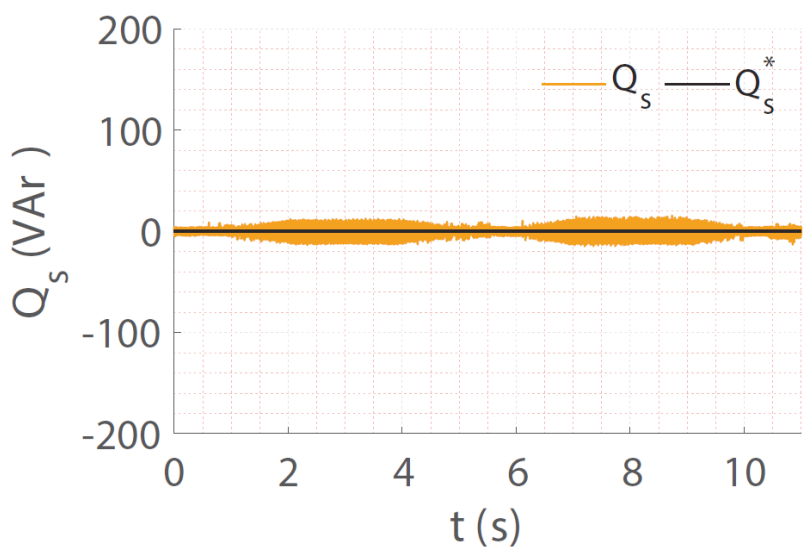

(b)

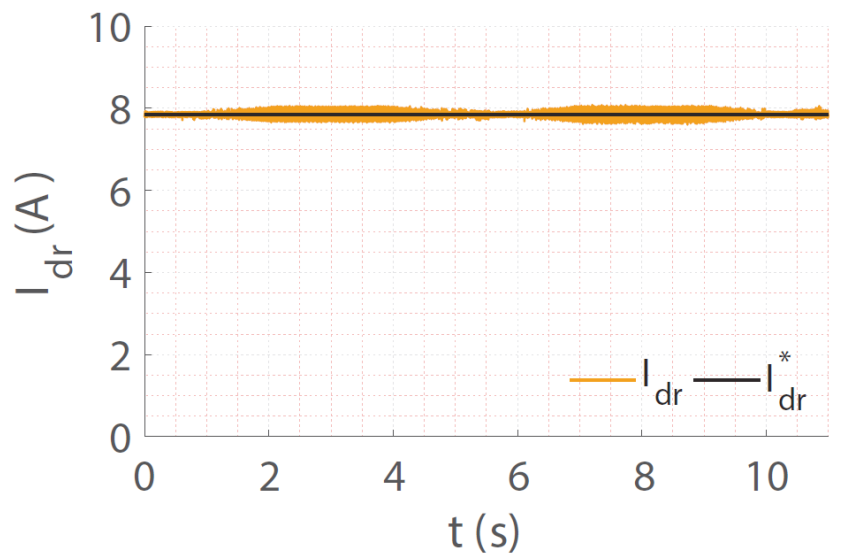

(d)

Fig. 25 DFIG direct power control (PI); (a) Stator active power $\left(P_{s}\right)$; (b) Stator reactive power $\left(Q_{s}\right)$; (c) Quadrature rotor current $\left(I_{q r}\right)$; (d) Direct rotor current $\left(I_{d r}\right)$

influences between both $d q$ axes, thanks to the decoupled model provided by the FOC. The SMC results have more noises because of the chattering.

Fig. 28 illustrates the output of the current controllers, that consequently control the power injected to the grid.
The huge chattering on the output $\left(V_{d r}, V_{q r}\right)$ of the SMC current controllers is due to the very high frequency of the discontinuous control law (Fig. 28 (b)), which can damage the system. The bandwidth of the SMC voltages depends mainly on the values of the SMC controller 


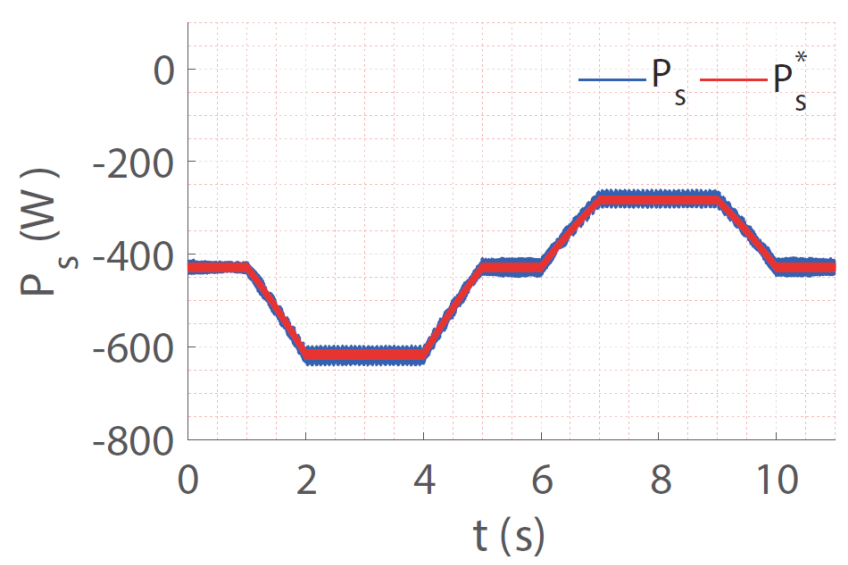

(a)

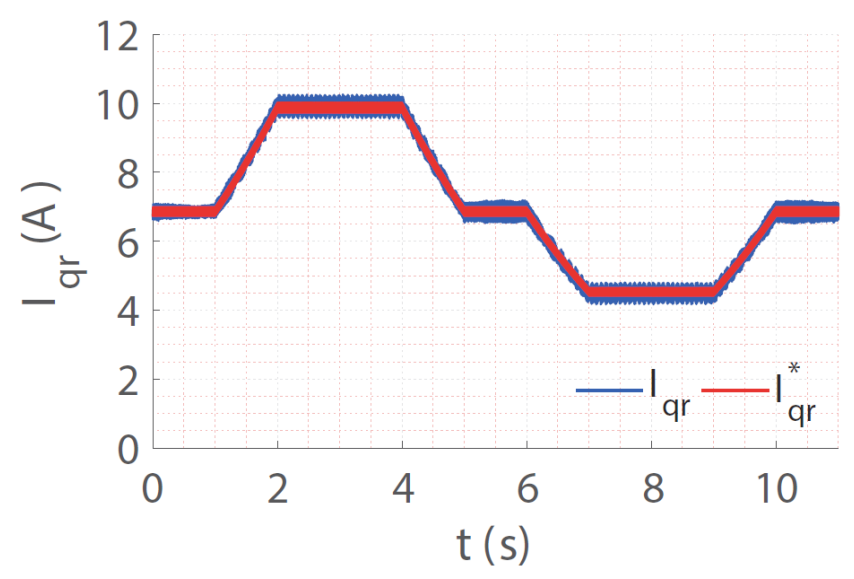

(c)

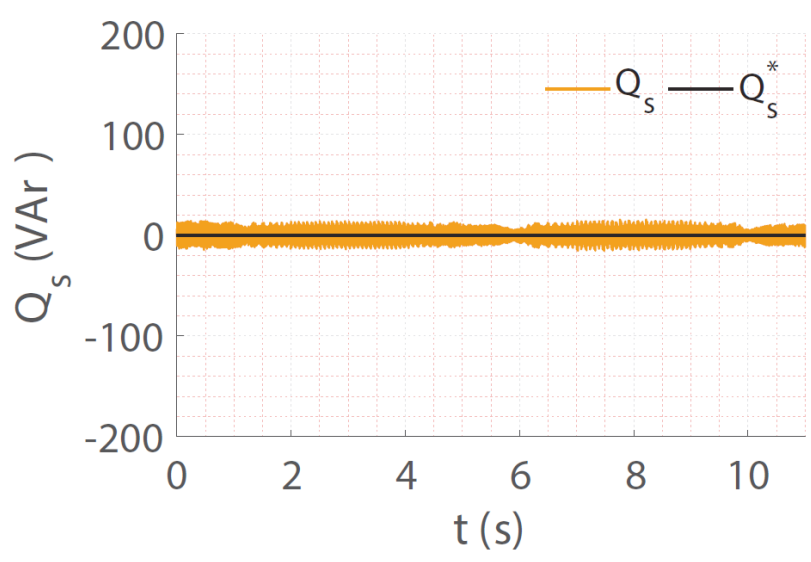

(b)

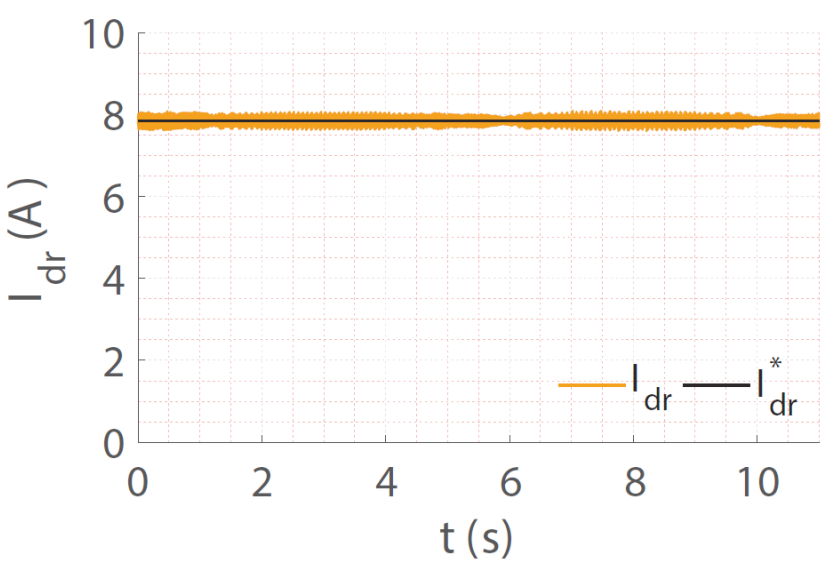

(d)

Fig. 26 DFIG direct power control (SMC); (a) Stator active power $\left(P_{s}\right)$; (b) Stator reactive power $\left(Q_{s}\right)$; (c) Quadrature rotor current $\left(I_{q r}\right)$; (d) Direct rotor current $\left(I_{d r}\right)$

parameters. The ST controller output presents less variations (Fig. 28 (c)), while the PI voltages seems perfect due to its limited output frequency (Fig. 28 (a)) but this controller has also a slow reaction to current disturbances.

The low value of the tracking error of both currents control loops demonstrates the efficiency of the performances of the controllers. The tracking errors harmonics are linked to the currents and voltages measurements, and mainly on the inverter noises, which clearly affects the quality of the stator power. Additionally, SMC tracking errors are noisier, while that of PI and SMCST are almost similar Figs. 29 and 30.

The system control performance can be evaluated quantitatively using performance indexes, such as Integral Absolute Error (IAE) and Integral Square Error (ISE). Table 1 shows the IAE and the ISE value obtained using analytical technique. Each of them represents a different norm of the time varying output error that converges to zero if the control is stable. The IAE and ISE indices show that the PI and SMC controllers allow a good convergence. Generally, the statistical comparison gives the advantage to the super twisting approach in terms of stability. Regarding the SMC indices values, they are above normal in comparison to other controllers. This suggests that they may create system stability issues during the experimental tests (see more in Tables 2 and 3 within the Appendix).

The simulation results show that the control algorithm developed by super twisting based high order sliding mode achieves good decoupling, power adjustment and tracking of the imposed reference values. As a result, we can validate the proposed control approach for each converter and the simulation model that is established. In addition, the comparison between the results from the PI regulation and those from the sliding mode control show a great resemblance based on the dynamic behavior. However, the sliding mode control has two main advantages, namely the robustness and the ease of the numerical implementation of the control law. The super twisting algorithm has 


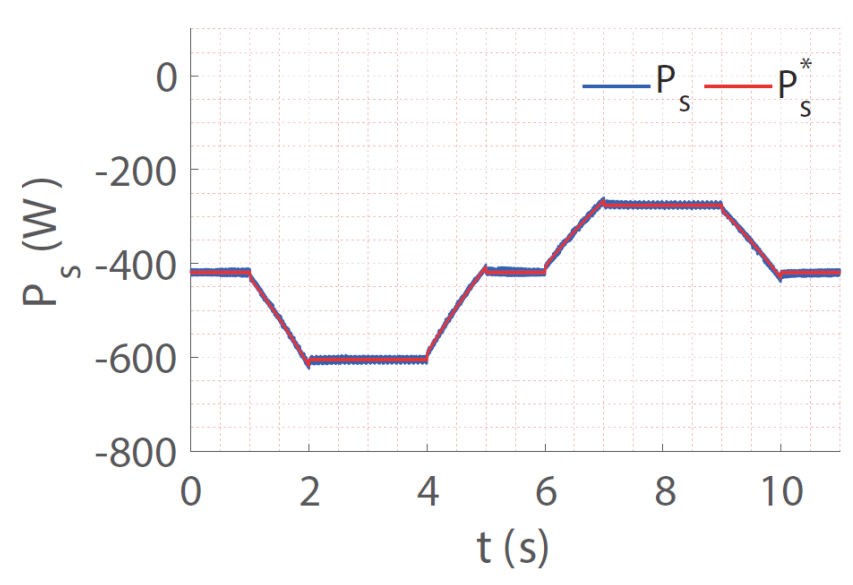

(a)

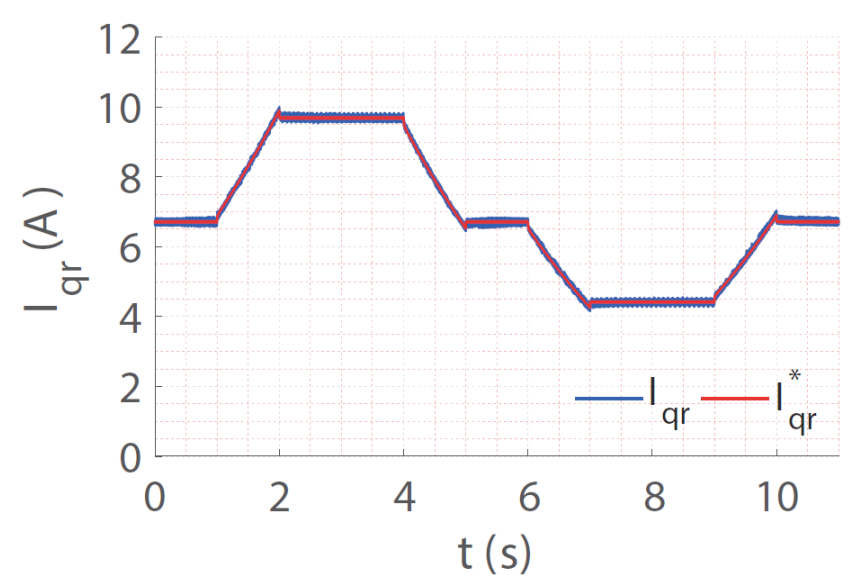

(c)

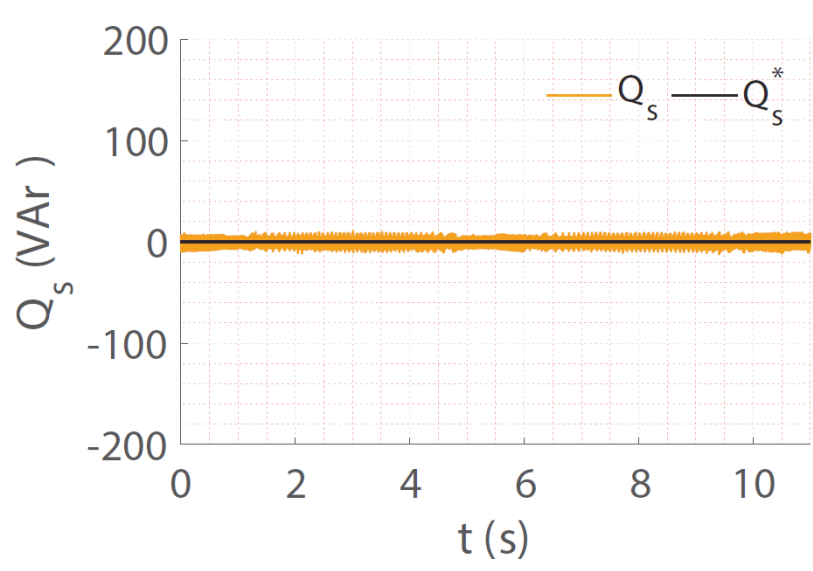

(b)

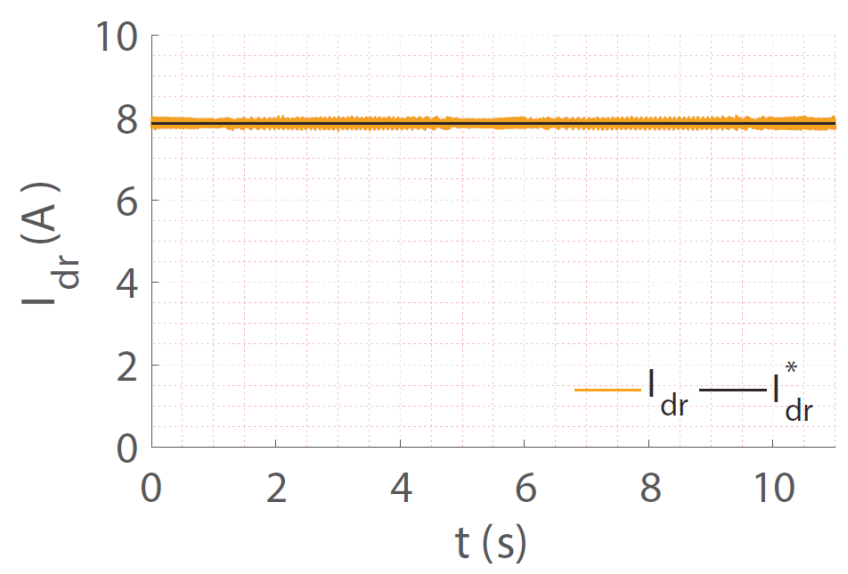

(d)

Fig. 27 DFIG direct power control (ST); (a) Stator active power $\left(P_{s}\right)$; (b) Stator reactive power $\left(Q_{s}\right)$; (c) Quadrature rotor current $\left(I_{q r}\right)$; (d) Direct rotor current $\left(I_{d r}\right)$

more advantages, namely the robustness and the ease of numerical implementation of the control law, add to this, the effective reduction of chattering and the total independence of the controller parameters from internal and external machine parameters.

\section{Conclusion}

In this work, a comparative study to realize the DFIG direct power control is investigated. Both linear and nonlinear control laws are applied on the rotor current loops to manage the stator powers. The adaptation of mechanical drive via the MPPT algorithm. Classical PI based DPC shows high dynamic control performances at steady state, but the sensitivity to parameter variations and disturbances limits its performances. Hence, the first order sliding mode mitigates this sensibility. The high-frequency oscillations induce chattering that affects the control performances and might damage the system. The simulation results of the improved high order sliding mode controller demonstrate the effectiveness of the proposed controller in terms of fast convergent velocity, reducing chattering phenomenon and simplicity to implement. The super twisting algorithm is implemented in order to improve the DFIG direct power control under random operating modes with less chattering as well as a parameter dependency of the controller, such as stator inductance and stator resistance. For the future works, the obtained results will be validated experimentally next on the prepared lab workbench.

\section{Acknowledgement}

This work is supported by the Direction Générale de la Recherche Scientifique et du Développement Technologique (DG RSDT), Algeria. 


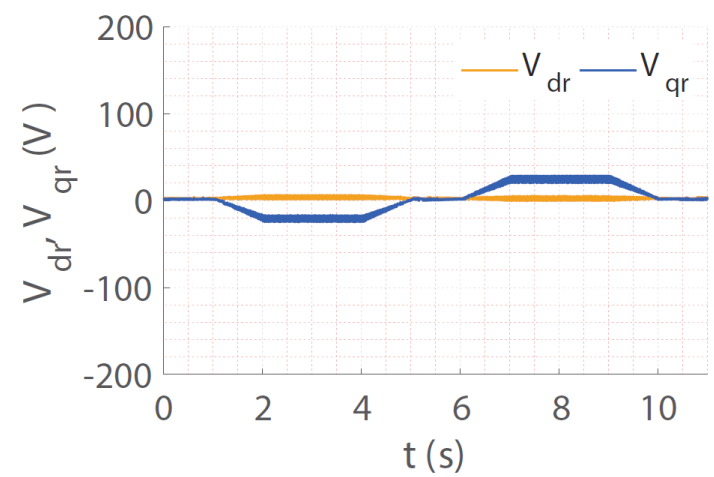

(a)

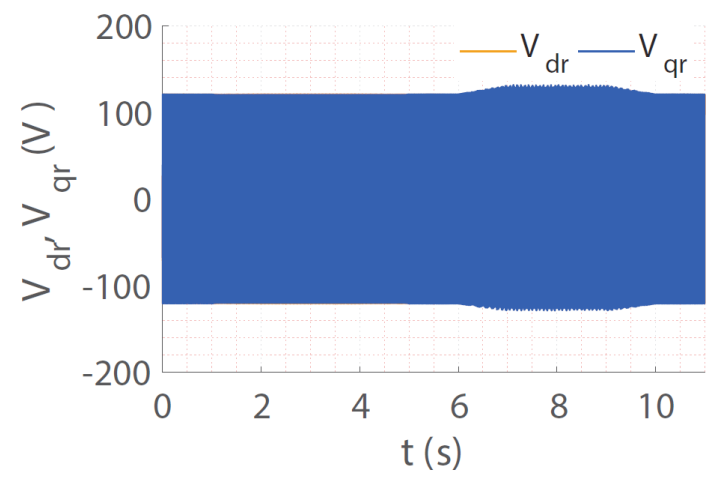

(b)

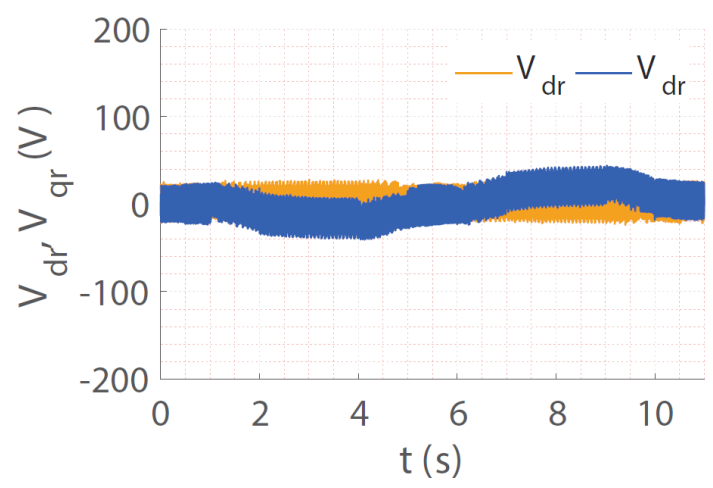

(c)

Fig. 28 DFIG Rotor voltages; (a) PI (b) SMC (c) ST

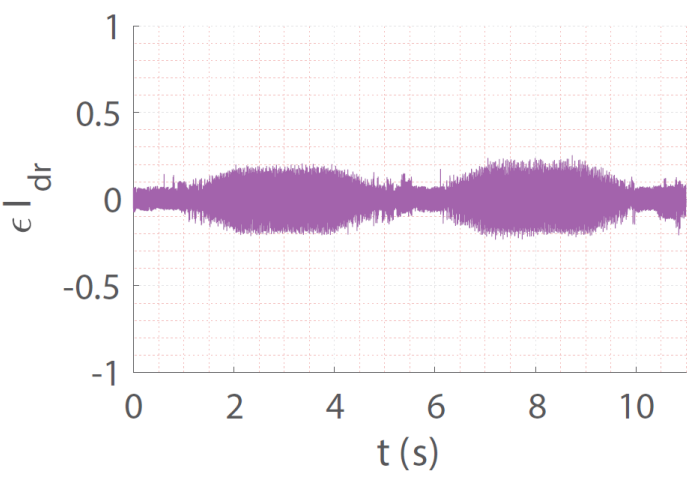

(a)

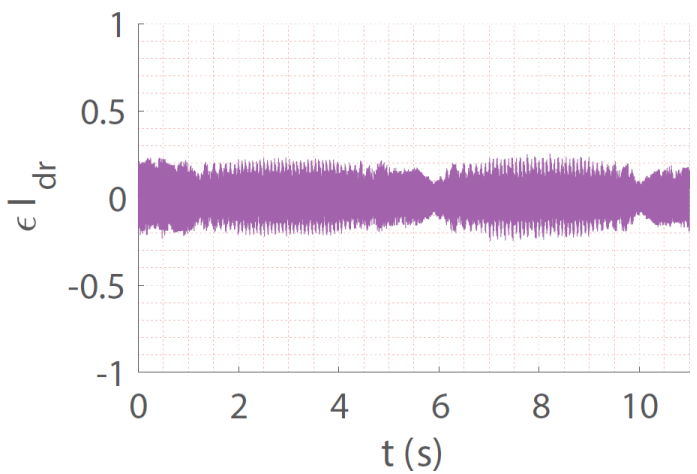

(b)

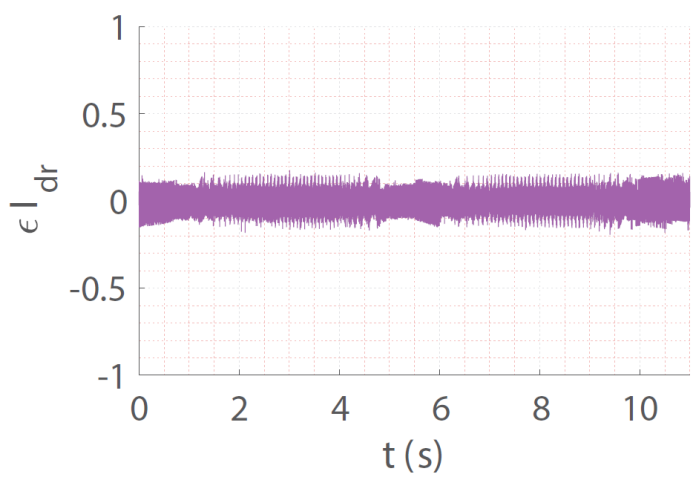

(c)

Fig. 29 DFIG Current tracking error ( $I_{d r}$ tracking error); (a) PI; (b) SMC; (c) ST 


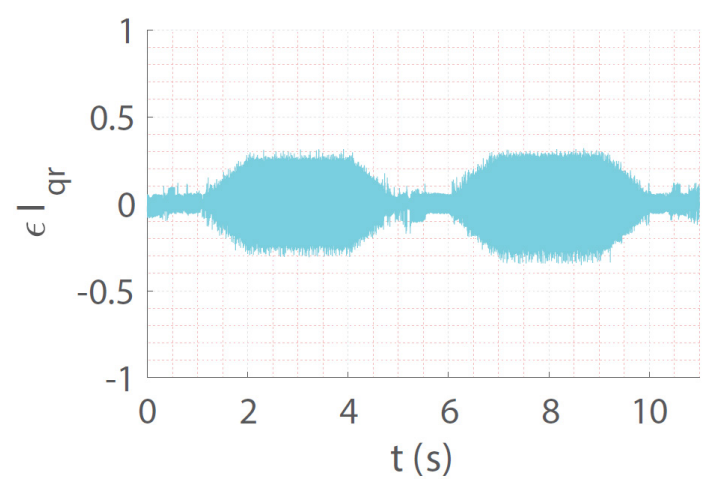

(a)

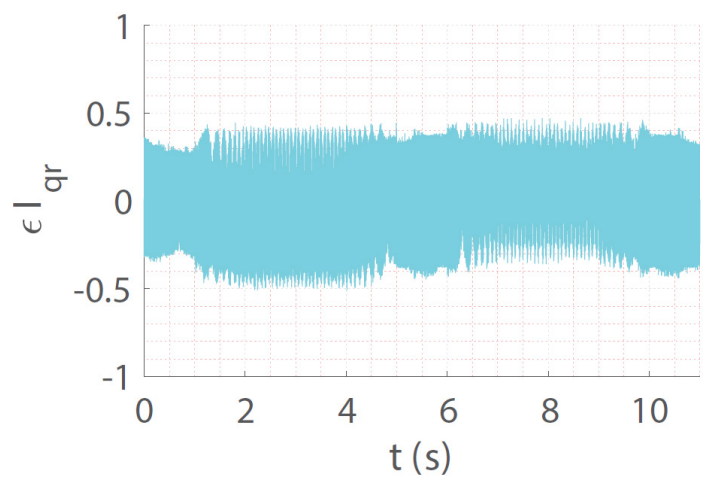

(b)

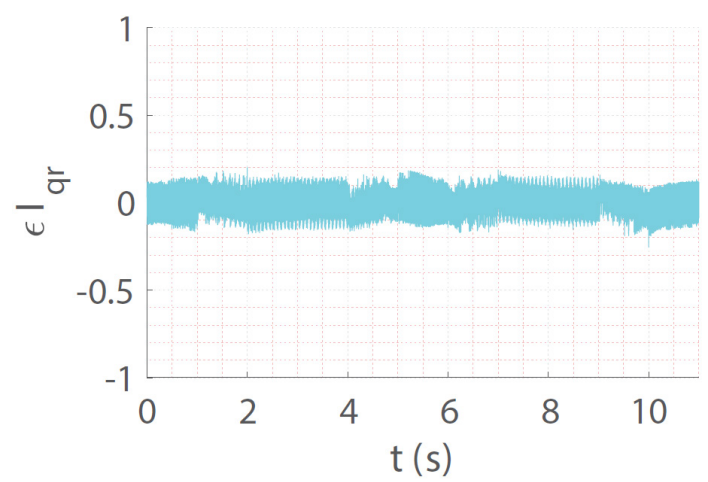

(c)

\begin{tabular}{lcccc}
\multicolumn{5}{c}{ Table 1 IAE and ISE indices } \\
\hline Indices & Error & PI & SMC & SMCST \\
\hline \multirow{4}{*}{ IAE } & $\varepsilon_{I_{q r}}$ & 0.4389 & 26.82 & 0.5996 \\
& $\varepsilon_{I_{d r r}}$ & 0.3195 & 25.77 & 0.5170 \\
& $\varepsilon_{\omega}$ & 23.5 & 93.03 & 0.6616 \\
\multirow{4}{*}{ ISE } & $\varepsilon_{I_{q r}}$ & 0.1439 & 1312 & 0.1790 \\
& $\varepsilon_{I_{d r}}$ & 0.07264 & 1374 & 0.1429 \\
& $\varepsilon_{\omega}$ & 1141 & 9767 & 55.79 \\
\hline
\end{tabular}

\section{Nomenclature}

DFIG

WPS

WECS

MPPT

TSR

$\mathrm{T}_{\text {DFIG }}$

$\mathrm{T}_{\mathrm{t}}$

$\mathrm{J}$

$\mathrm{f}$

V

$\mathrm{C}_{\mathrm{P}}$

$\mathrm{R}$

$\mathrm{G}$

$\lambda$

$\beta$

$\Omega_{m}$

$\rho$
Double fed induction generator

Wind power system

Wind energy conversion system

Maximum power point tracking

Tip speed ratio

DFIG electromagnetic torque

Turbine torque

Moment of inertia

Viscous friction coefficient

Wind speed, $\mathrm{m} / \mathrm{s}$

Power coefficient

Blade radius, $\mathrm{m}$

Gear box ratio

The tip speed ratio

The blade pitch angle

The mechanical speed, rpm

Air density, $\mathrm{kg} / \mathrm{m}^{3}$

Fig. 30 DFIG Current tracking error $\left(I_{q r}\right.$ tracking error); (a) PI; (b) SMC; (c) ST 


\section{References}

[1] Global Wind Energy Council "Global wind report 2019", [online] Available at: http://www.gwec.net/ [Accessed: 25 June 2020]

[2] Blaabjerg, F., Xu, D., Chen, W., Zhu N. "Advanced Control Of Doubly Fed Induction Generator For Wind Power Systems", WileyIEEE Press, Hoboken, NJ, USA, 2018. https://doi.org/10.1002/9781119172093

[3] Dekali, Z., Baghli, L., Boumediene, A. "Indirect power control for a Grid Connected Double Fed Induction Generator Based Wind Turbine Emulator", In: 2019 International Conference on Advanced Electrical Engineering (ICAEE), Algiers, Algeria, 2019, pp. 1-6. https://doi.org/10.1109/ICAEE47123.2019.9014778

[4] Hussain, J., Mishra, M. K. "Adaptive Maximum Power Point Tracking Control Algorithm for Wind Energy Conversion Systems", IEEE Transactions on Energy Conversion, 31(2), pp. 697-705, 2016. https://doi.org/10.1109/TEC.2016.2520460

[5] Zhang, Y., Liu, H., Mantooth, H. A. "Control strategy of high power converters with synchronous generator characteristics for PMSG-based wind power application", In: 2016 IEEE Applied Power Electronics Conference and Exposition, Long Beach, CA, USA, 2016, pp. 3180-3184.

https://doi.org/10.1109/APEC.2016.7468319

[6] Llano, D., Tatlow, M., McMahon, R. "Control algorithms for permanent magnet generators evaluated on a wind turbine emulator test-rig", In: 7th IET International Conference on Power Electronics, Machines and Drives, Manchester, UK, 2014, Article number: 4.4.04.

https://doi.org/10.1049/cp.2014.0304

[7] Shehata, E. G. "Sliding mode direct power control of RSC for DFIGs driven by variable speed wind turbines", Alexandria Engineering Journal, 54(4), pp. 1067-1075, 2015.

https://doi.org/10.1016/j.aej.2015.06.006

[8] Djilali, L., Sanchez, E. N., Belkheiri, M. "First and High Order Sliding Mode Control of a DFIG-Based Wind Turbine", Electric Power Components and Systems, 48(1-2), pp. 105-116, 2020. https://doi.org/10.1080/15325008.2020.1758836

[9] Dekali, Z., Baghli, L., Boumediene, A., Djemai, M. "Control of a Grid Connected DFIG Based Wind Turbine Emulator", In: 2018 5th International Symposium on Environment-Friendly Energies and Applications, Rome, Italy, 2018, pp. 1-6.

https://doi.org/10.1109/EFEA.2018.8617049

[10] Zouggar, E. O., Chaouch, S., Abdeslam, D., Abdelhamid, A. "Sliding Control with Fuzzy Type-2 Controller of Wind Energy System Based on Doubly Fed Induction Generator", Instrumentation Mesure Métrologie, 18(2), pp. 137-146, 2019. https://doi.org/10.18280/i2m.180207

[11] Yaichi, I., Semmah, A., Wira, P. "Control of Doubly Fed Induction Generator with Maximum Power Point Tracking for Variable Speed Wind Energy Conversion Systems", Periodica Polytechnica Electrical Engineering and Computer Science, 64(1), pp. 87-96, 2020.

https://doi.org/10.3311/PPee.14166

[12] ur Rehman, A., Ali, N., Khan, O., Pervaiz, M. "A Disturbance Observer Based Sliding Mode Control for Variable Speed Wind Turbine", IETE Journal of Research, pp. 1-8, 2019.

https://doi.org/10.1080/03772063.2019.1676661
[13] Belounis, O., Labar, H. "Fuzzy Sliding Mode Controller of DFIG for Wind Energy Conversion", International Journal of Intelligent Engineering and Systems, 10(2), pp. 163-172, 2017.

https://doi.org/10.22266/ijies2017.0430.18

[14] Mbukani, M. W. K., Gule, N. "Evaluation of an STSMO-based estimator for power control of rotor-tied DFIG systems", IET Electric Power Applications, 13(11), pp. 1871-1882, 2019. https://doi.org/10.1049/iet-epa.2019.0035

[15] Dekali, Z., Baghli, L., Boumediene, A. "Experimental Emulation of a Small Wind Turbine Under Operating Modes Using DC Motor", In: 2019 4th International Conference on Power Electronics and their Applications (ICPEA), Elazig, Turkey, 2019, pp. 1-5. https://doi.org/10.1109/ICPEA1.2019.8911194

[16] Moussa, I., Bouallegue, A., Khedher, A. "New wind turbine emulator based on DC machine: hardware implementation using FPGA board for an open-loop operation", IET Circuits, Devices \& Systems, 13(6), pp. 896-902, 2019. https://doi.org/10.1049/iet-cds.2018.5530

[17] Chikha, S., Barra, K. "Predictive Control of Variable Speed Wind Energy Conversion System with Multi Objective Criterions", Periodica Polytechnica Electrical Engineering and Computer Science, 60(2), pp. 96-106, 2016. https://doi.org/10.3311/PPee.8873

[18] Paul, S., Naidu, D. S. "Nonlinear Optimal Tracking Control of Wind Energy Conversion System in Partial Load Region", In: 2019 North American Power Symposium (NAPS), Wichita, KS, USA, 2019, pp. 1-6. https://doi.org/10.1109/NAPS46351.2019.9000319

[19] Saidi, Y., Mezouar, A., Miloud, Y., Brahmi, B., Kerrouche, K. D. E., Benmahdjoub, M. A. "Adaptive Maximum Power Control Based on Optimum Torque Method for Wind Turbine by Using Fuzzy-Logic Adaption Mechanisms during Partial Load Operation", Periodica Polytechnica Electrical Engineering and Computer Science, 64(2), pp. 170-178, 2020. https://doi.org/10.3311/PPee.15155

[20] Martinez, F., Herrero, L. C., de Pablo, S. "Open loop wind turbine emulator", Renewable Energy, 63, pp. 212-221, 2014. https://doi.org/10.1016/j.renene.2013.09.019

[21] Imran, R. M., Hussain, D. M. A., Soltani, M. "DAC with LQR control design for pitch regulated variable speed wind turbine", In: 2014 IEEE 36th International Telecommunications Energy Conference, Vancouver, BC, Canada, 2014, pp. 1-6. https://doi.org/10.1109/INTLEC.2014.6972153

[22] Martínez-Márquez, C. I., Twizere-Bakunda, J. D., LundbackMompó, D., Orts-Grau, S., Gimeno-Sales, F. J., Seguí-Chilet, S. "Small Wind Turbine Emulator Based on Lambda-Cp Curves Obtained under Real Operating Conditions", Energies, 12(13), Article number: 2456, 2019. https://doi.org/10.3390/en12132456

[23] Moness, M., Moustafa, A. M. "Real-Time Switched Model Predictive Control for a Cyber-Physical Wind Turbine Emulator", IEEE Transactions on Industrial Informatics, 16(6), pp. 3807-3817, 2020.

https://doi.org/10.1109/TII.2019.2937549 
[24] Barrios Aguilar, M. E., Coury, D. V., Reginatto, R., Monaro, R. M. "Multi-objective PSO applied to PI control of DFIG wind turbine under electrical fault conditions", Electric Power Systems Research, 180, Article number: 106081, 2020. https://doi.org/10.1016/j.epsr.2019.106081

[25] Amer, M., Miloudi, A., Lakdja, F. "Optimal DTC Control Strategy of DFIG Using Variable Gain PI and Hysteresis Controllers Adjusted by PSO Algorithm", Periodica Polytechnica Electrical Engineering and Computer Science, 64(1), pp. 74-86, 2020. https://doi.org/10.3311/PPee.14237

[26] Moulay, F., Habbatti, A., Hamdaoui, H. "Application and Control of a Doubly Fed Induction Machine Integrated in Wind Energy System", Instrumentation Mesure Métrologie, 18(3), pp. 257-265, 2019.

https://doi.org/10.18280/i2m.180305

[27] Amrane, F., Chaiba, A., Babes, B. E., Mekhilef, F. "Design And Implementation of High Performance Field Oriented Control for GridConnected Doubly Fed Induction Generator Via Hysteresis Rotor Current Controller", Revue Roumaine Des Sciences Techniques Série Électrotechnique et Énergétique, 61(4), pp. 319-324, 2016. [online] Available at: http://revue.elth.pub.ro/index.php?action=main\&year $=2016 \&$ issue $=4$ [Accessed: 20 June 2020]

[28] Dekali, Z., Baghli, L., Boumediene, A. "Experimental Implantation of an Emulator of a Wind Energy Conversion Chain System Based on Double Fed Induction Generator", In: 11th Scientific and Technical Days Innovation and Partnership in a Global Context of Energy Transition, Oran, Algeria, 2018, pp. 1-8.

[29] Abad, G., López, J., Rodríguez, M. A., Marroyo, L., Iwanski, G. "Doubly Fed Induction Machine: Modeling and Control for Wind Energy Generation", John Wiley \& Sons, Hoboken, NJ, USA, 2011. https://doi.org/10.1002/9781118104965

[30] Mechter, A., Kemih, K., Ghanes, M. "Sliding Mode Control of a Wind Turbine with Exponential Reaching Law", Acta Polytechnica Hungarica, 12(03), pp. 167-183, 2015. https://doi.org/10.12700/APH.12.3.2015.3.10

[31] Saihi, L., Berbaoui, B., Glaoui, H., Djilali, L., Abdeldjalil, S. "Robust Sliding Mode Ho Controller of DFIG Based on Variable Speed Wind Energy Conversion System, Periodica Polytechnica Electrical Engineering and Computer Science, 64(1), pp. 53-63, 2020.

https://doi.org/10.3311/PPee.14490
[32] Yaichi, I., Semmah, A., Wira, P., Djeriri, Y. "Super-twisting Sliding Mode Control of a Doubly-fed Induction Generator Based on the SVM Strategy", Periodica Polytechnica Electrical Engineering and Computer Science, 63(3), pp. 178-190, 2019. https://doi.org/10.3311/PPee.13726

[33] Guo, L., Wang, D., Peng, Z., Diao, L. "Improved super-twisting sliding mode control of a stand-alone DFIG-DC system with harmonic current suppression", IET Power Electronics, 13(7), pp. 1311-1320, 2020.

https://doi.org/10.1049/iet-pel.2019.0691

[34] Dendouga, A. "A Comparative Study Between the PI and SM Controllers Used by Nonlinear Control of Induction Motor Fed by SVM Matrix Converter", IETE Journal of Research, pp. 1-11, 2020. https://doi.org/10.1080/03772063.2020.1743781

[35] Xiong, L., Li, P., Wang, J. "High-order sliding mode control of DFIG under unbalanced grid voltage conditions", International Journal of Electrical Power \& Energy Systems, 117, Article number: $105608,2020$. https://doi.org/10.1016/j.ijepes.2019.105608

[36] Horch, M., Boumédiène, A., Baghli, L. "Sensorless high-order sliding modes vector control for induction motor drive with a new adaptive speed observer using super-twisting strategy", International Journal of Computer Applications in Technology, 60(2), pp. 144-153, 2019. https://doi.org/10.1504/IJCAT.2019.100131

[37] Karabacak, M., Fernández-Ramrez, L. M., Kamal, T., Kamal, S. "A New Hill Climbing Maximum Power Tracking Control for Wind Turbines With Inertial Effect Compensation", IEEE Transactions on Industrial Electronics, 66(11), pp. 8545-8556, 2019. https://doi.org/10.1109/TIE.2019.2907510

[38] Moradi, H., Alinejad-Beromi, Y., Yaghobi, H., Bustan, D. "Sliding mode type-2 neuro-fuzzy power control of grid-connected DFIG for wind energy conversion system", IET Renewable Power Generation, 13(13), pp. 2435-2442, 2019. https://doi.org/10.1049/iet-rpg.2019.0066 


\section{Appendix}

The simulation experiments are being investigated using a $1.5 \mathrm{~kW}$ WTS generator. The parameters of our framework are displayed in a table format.

\begin{tabular}{lc}
\multicolumn{2}{c}{ Table 2 Wind turbine settings } \\
\hline Settings & Parameters \\
\hline Rated power $P_{n}(\mathrm{~kW})$ & 1.5 \\
Nominal speed $(\mathrm{rpm})$ & 1500 \\
Blade radius $R(\mathrm{~m})$ & 3 \\
Gearbox ratio & 7 \\
Air density $\left(\mathrm{kg} / \mathrm{m}^{3}\right)$ & 1.225 \\
\hline \multicolumn{1}{c}{ Table 3 DFIG settings } \\
\hline Settings & Parameters \\
\hline Rated power $P_{n}(\mathrm{~kW})$ & 1.5 \\
Nominal speed $(\mathrm{rpm})$ & 1500 \\
Stator resistance $R_{s}(\Omega)$ & 3.6 \\
Rotor resistance $R_{r}(\Omega)$ & 0.337 \\
Stator inductance $L_{s}(\mathrm{mH})$ & 0.1232 \\
Rotor inductance $L_{r}(\mathrm{mH})$ & 0.1122 \\
Mutual inductance $L_{m}(\mathrm{mH})$ & 0.1118 \\
Turns ratio $\sigma$ & 0.0957 \\
\hline
\end{tabular}

